\title{
Finding Potential Adverse Events in the Unstructured Text of Electronic Health Care Records: Development of the Shakespeare Method
}

Roselie A Bright ${ }^{1}$, MS, ScD; Summer K Rankin ${ }^{2}, \mathrm{PhD}$; Katherine Dowdy ${ }^{2}$, BA; Sergey V Blok ${ }^{2}$, PhD; Susan J Bright ${ }^{3}$, MPH, DVM; Lee Anne M Palmer ${ }^{3}$, MPH, VMD

\author{
${ }^{1}$ US Food and Drug Administration, Silver Spring, MD, United States \\ ${ }^{2}$ Booz Allen Hamilton, McLean, VA, United States \\ ${ }^{3}$ US Food and Drug Administration, Rockville, MD, United States
}

\section{Corresponding Author:}

Summer K Rankin, PhD

Booz Allen Hamilton

8283 Greensboro Dr

McLean, VA, 22102

United States

Phone: 18085945975

Email: rankin summer@bah.com

\section{Related Articles:}

Preprint (medRxiv): https://www.medrxiv.org/content/10.1101/2021.01.05.21249239v1

Preprint (JMIR Preprints): https://preprints.jmir.org/preprint/27017

Peer-Review Report by Anonymous: https://med.jmirx.org/2021/3/e31547/

Peer-Review Report by Anonymous: https://med.jmirx.org/2021/3/e31548/

Peer-Review Report by Mark Antoniou: https://med.jmirx.org/2021/3/e31550/

Peer-Review Report by Haiyan Yu: https://med.jmirx.org/2021/3/e31551/

Authors' Response to Peer-Review Reports: https://med.jmirx.org/2021/3/e31568/

\begin{abstract}
Background: Big data tools provide opportunities to monitor adverse events (patient harm associated with medical care) (AEs) in the unstructured text of electronic health care records (EHRs). Writers may explicitly state an apparent association between treatment and adverse outcome ("attributed") or state the simple treatment and outcome without an association ("unattributed"). Many methods for finding AEs in text rely on predefining possible AEs before searching for prespecified words and phrases or manual labeling (standardization) by investigators. We developed a method to identify possible AEs, even if unknown or unattributed, without any prespecifications or standardization of notes. Our method was inspired by word-frequency analysis methods used to uncover the true authorship of disputed works credited to William Shakespeare. We chose two use cases, "transfusion" and "time-based." Transfusion was chosen because new transfusion AE types were becoming recognized during the study data period; therefore, we anticipated an opportunity to find unattributed potential AEs (PAEs) in the notes. With the time-based case, we wanted to simulate near real-time surveillance. We chose time periods in the hope of detecting PAEs due to contaminated heparin from mid-2007 to mid-2008 that were announced in early 2008. We hypothesized that the prevalence of contaminated heparin may have been widespread enough to manifest in EHRs through symptoms related to heparin AEs, independent of clinicians' documentation of attributed AEs.
\end{abstract}

Objective: We aimed to develop a new method to identify attributed and unattributed PAEs using the unstructured text of EHRs.

Methods: We used EHRs for adult critical care admissions at a major teaching hospital (2001-2012). For each case, we formed a group of interest and a comparison group. We concatenated the text notes for each admission into one document sorted by date, and deleted replicate sentences and lists. We identified statistically significant words in the group of interest versus the comparison group. Documents in the group of interest were filtered to those words, followed by topic modeling on the filtered documents to produce topics. For each topic, the three documents with the maximum topic scores were manually reviewed to identify PAEs. 
Results: Topics centered around medical conditions that were unique to or more common in the group of interest, including PAEs. In each use case, most PAEs were unattributed in the notes. Among the transfusion PAEs was unattributed evidence of transfusion-associated cardiac overload and transfusion-related acute lung injury. Some of the PAEs from mid-2007 to mid-2008 were increased unattributed events consistent with AEs related to heparin contamination.

Conclusions: The Shakespeare method could be a useful supplement to AE reporting and surveillance of structured EHR data. Future improvements should include automation of the manual review process.

(JMIRx Med 2021;2(3):e27017) doi: 10.2196/27017

\section{KEYWORDS}

epidemiology; electronic health record; electronic health care record; big data; patient harm; patient safety; public health; product surveillance, postmarketing; natural language processing; proof-of-concept study; critical care

\section{Introduction}

\section{Background}

Avoidable patient harm continues to be a significant problem [1]. To learn of adverse events (AEs), that is, patient harm, related to US Food and Drug Administration (FDA)-regulated products, the FDA relies on spontaneous reports from manufacturers, health care providers, and the general public. Published deficiencies of these reports [2-10] include nonstatistical representativeness of harm and problems. Now that electronic health care records (EHRs) are very common [11] and often more informative than billing codes from payment claims $[7,12,13]$, we have an opportunity to leverage them for automated surveillance of patient harm $[3,7,14,15]$. We had two inspirations for naming the method after William Shakespeare: (1) in his play Macbeth [16], a king named Macbeth is surprised by an attack on his castle by soldiers camouflaged by trees, even though he had been warned that his downfall would come when the woods moved; and (2) scholars have been using word-frequency methods to discuss the true authorship of works from Shakespeare's time [17].

\section{EHRs for Postmarketing Surveillance}

Many methods for finding prespecified AEs in text [6,7,9,18-40] rely on predefining potential AEs (PAEs) before searching for prespecified words and phrases or manual labeling (standardization) by investigators. Crucially, events described in text may not necessarily be attributed to AEs [14,25,41]. We wanted to develop a method to identify PAEs, even if unknown or unattributed, without any prespecifications or standardization of notes.

There are many challenges to automated use of EHRs:

- Diagnosis codes may be "invalid, insensitive or non-specific" [20]

- "Often the notes contain medical and non-medical abbreviations, acronyms, numbers and misspelled words, which make it difficult to recognize the critical information in the notes. In other words, certain types of information such as ADEs [adverse drug events], indications, and signs and symptoms are harder to detect than other information such as drug names" [24]

- Medical entities in EHRs notes "can span across multiple words" [24]
- “... there is a lot of ambiguity among relevant named entities. Depending upon the context, the same exact phrase can be an ADE, indication, or a sign and symptom" [24]

- Periods do not always indicate the end of a sentence ("Dr.," "1.23," etc) [24]

- “...notes are frequently ungrammatical and are often inconsistently formatted. Ambiguity is common: MS, for example, can mean mitral stenosis or multiple sclerosis" [12]

- EHRs are “...subject to access restrictions..." [6]

- “... $[\mathrm{N}]$ ot all events and outcomes are consistently captured..." [15]

- We observed that different medical specialties, nurses, and other health care providers used different vocabulary.

We used the Medical Information Mart for Intensive Care III (MIMIC-III) EHR data set $[42,43]$ because it is available to scientists with human subjects research training. MIMIC-III focuses on critical care in a major Boston teaching hospital. A published report using MIMIC-III noted [36]:

...several sentence segmentation tools available in
popular NLP [natural language processing] toolkits,
such as NLTK31 and spaCy, were tested and did not
work well in clinical notes. In clinical notes, sentences
do not always end with regular punctuation marks
such as a period or question mark. More specifically,
both regular punctuation marks and newline
characters can serve as sentence breakers; however,
newline characters can also be used for text wrap.
Moreover, enumeration-like and list-like formats are
also common in clinical notes, especially for physical
exam and list of medications.

Many medical care AEs occur at higher frequency in hospital critical care settings and are related to complex illnesses, invasive procedures, and relatively long lists of treatments $[44,45]$.

\section{General Methods}

\section{Preprocessing}

We used EHRs for critical care admissions within an adult hospital, the Beth Israel Deaconess Medical Center in Boston, MA. The Massachusetts Institute of Technology worked with the hospital to process EHRs from 2001 to 2012, including unstructured notes, into the MIMIC-III data set, which is publicly available to those meeting certification requirements. 
The research was designated as not human subjects research by the FDA Institutional Review Board under the Code of Federal Regulations, Title 45, Part 46 [46].

We removed admissions of patients aged <16 years and admissions without notes from the total of 58,976 hospital admissions, resulting in 49,284 admissions.

We noted during our initial manual review of the notes for dozens of admissions-to familiarize ourselves with the data-that discharge summaries did not include all PAE information in the progress notes. We decided to use all available notes for each study admission and created one document by concatenating them chronologically. The notes in the MIMIC-III database contained duplicated paragraphs, sentences, and lists. These duplications distort statistical analyses of terms used and hamper manual review of the notes. We applied the Bloatectomy package to remove the duplicate text from each admission document [47].

We removed the personally identifying information mask string and lowercased the text. We retained punctuation, numerals, and stop words because they convey clinical information and are sometimes components of abbreviations.

\section{The Shakespeare Method}

The Shakespeare method has five steps:

1. Convert each document into a vector of n-gram (term) frequencies.

2. Create groups of vectors: target and comparison.

3. Extract terms in the target group that are significant for the target group.

4. Apply topic analysis to the target group-filtered vectors.

5. Review the original documents that have topic scores of interest to interpret the topics and find PAEs.

We have published the code [48].

We selected two use cases to demonstrate the Shakespeare method: (1) comparing patients who received blood transfusion to those who did not and (2) comparing patient experiences in 1 year to the prior year. They shared step 1 (create n-gram vectors) of the Shakespeare method; we used the collocation detection skip-gram method for extracting the n-grams with $n=1-5$ consecutive words $[49,50]$ (Figure 1A). We vectorized each document using a bag-of-words representation, where each dimension is represented by the frequency (count) of each n-gram (Figure 1B), resulting in a set of 7,422,044 words.

Figure 1. The Shakespeare method process with truncated examples. Step 1 (create n-gram vectors) includes (A) n-grams (terms) and (B) form vectors. Step 2 (create two groups) is (C) form groups. Step 3 (extract significant terms) is (D) extracted terms and (E) trim vectors in the group of interest. Step 4 (model topics) includes (F) latent Dirichlet allocation (LDA) topic modeling and (G) topics to documents. Step 5 (review topics) includes (H) identification of exceptional instances.

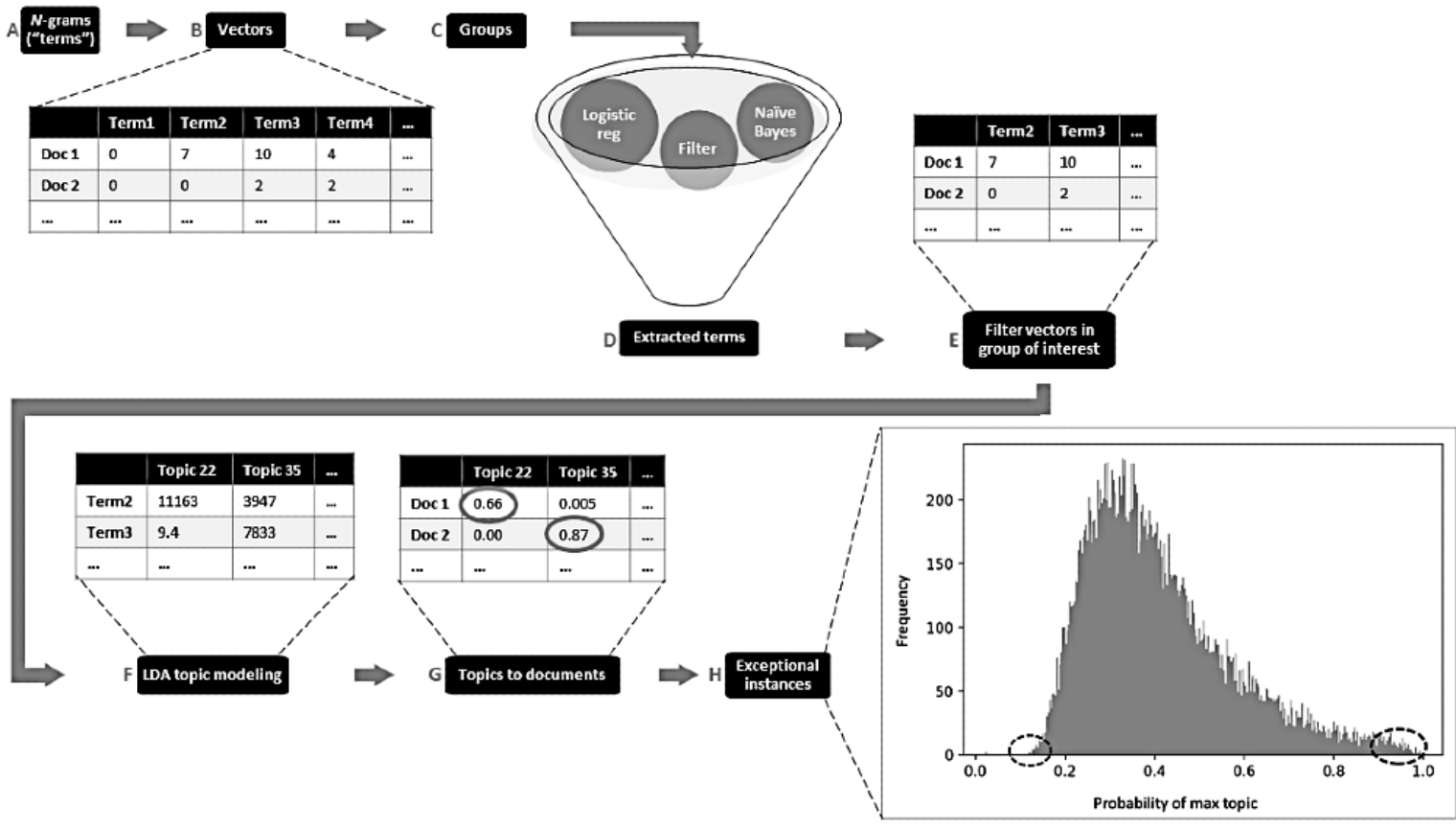

\section{The Transfusion Case}

\section{Introduction}

We decided to compare critical care patient admissions that involved blood transfusion (T) to comparison (C) admissions that had no transfusion events. An earlier version of the data set showed a higher risk of near-term mortality for patients receiving red blood cell transfusion compared to nontransfused patients [51]. By 2002, many transfusion AEs (TAEs) had been described [52]. During the time period covered by the data set, the transfusion research community recognized new TAE types-transfusion-related acute lung injury (TRALI) and transfusion-associated circulatory overload (TACO) - that prompted new guidelines to reduce the use of transfusion [53]. Simultaneously, far fewer reports were coming to the FDA than would have been expected, considering the level of professional concern [54-56]. 


\section{Study Objective}

Our objective was to develop a method of using EHR notes to find recognized and unrecognized potential TAEs (PTAEs), which incidentally might also uncover other anomalies. We wanted our method to operate in the setting of the above-noted challenges.

\section{Methods}

We followed step 1 (create n-gram vectors) as described in TheShakespeare Method subsection of the General Methods section.

\section{Transfusion Case Step 2: Create Groups}

We used the blood transfusion ( $n=21,443$ admissions) and comparison ( $\mathrm{n}=25,468$ admissions) groups described in prior work [57] (Figure 1C).

\section{Transfusion Case Step 3: Extract Significant Target Terms}

Our goal for steps 3 and 4 was to filter document vectors to only include terms that were significant to the transfused group and then model the topics within those terms in the transfused group to identify experiences emblematic of transfusion. We formalized the process of extracting these terms by looking at term coefficients associated with a classifier that learns to differentiate the two groups. We underwent an iterative process of trying multiple hyperparameters and classification models to identify these terms. We observed that an ensemble of two classification methods (naïve Bayes [NB] and logistic regression [LR]) and filtering [58-62] was useful for capturing common, infrequent, and rare terms that were significant for $\mathrm{T}$. This term selection resulted in 41,664 terms (Figure 2). We reduced the T document vectors to include only the 41,664 terms (see Figure $1 \mathrm{E}$ for a truncated example).

Figure 2. Flowchart of the embedded-based and filter-based term selection processes for the transfusion case. T: transfusion, C: comparison.

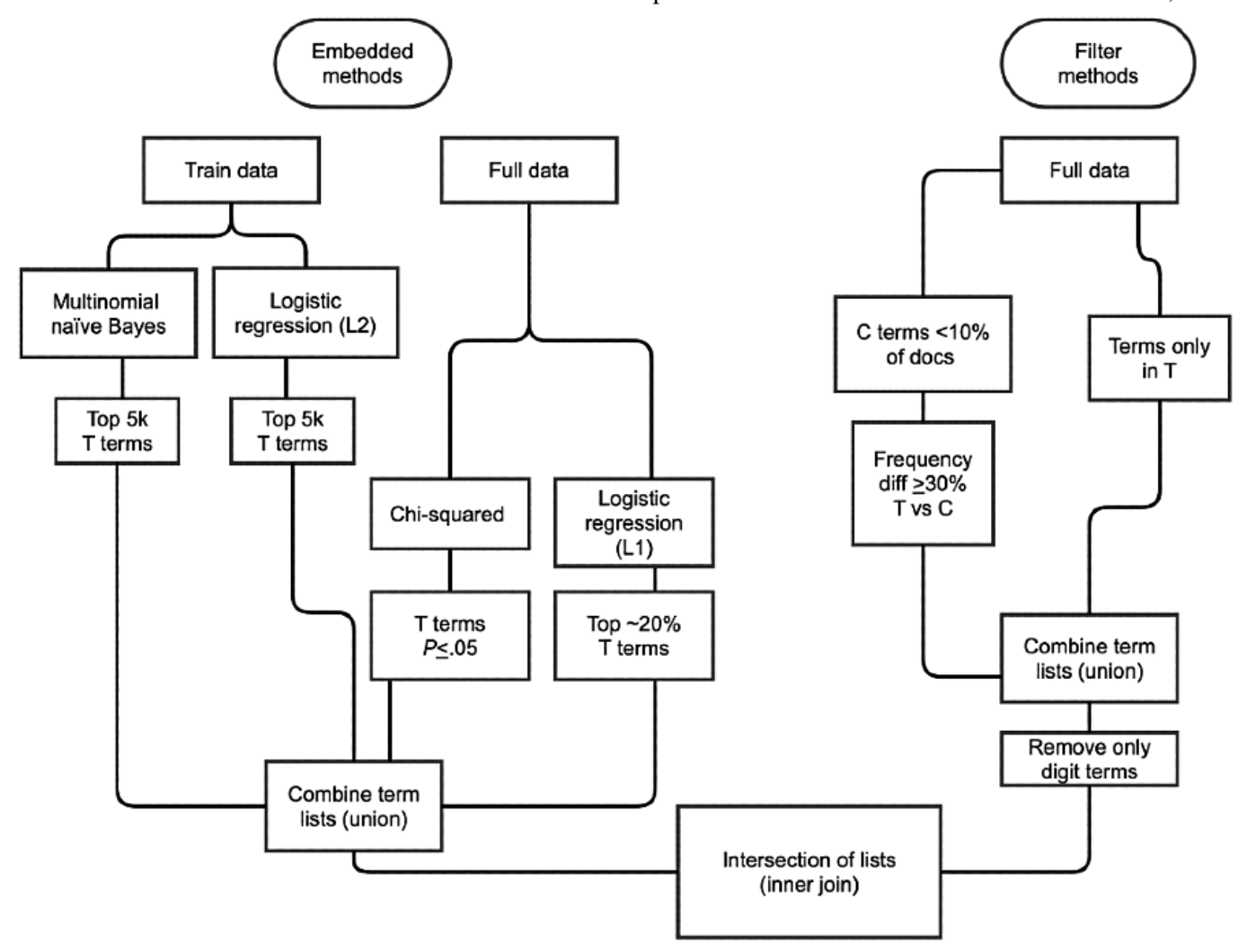

\section{Transfusion Case Step 4: Model Topics}

Topic modeling is an unsupervised method commonly used in NLP to extract the most relevant terms for each topic (cluster) of similar documents [63,64]. We chose latent Dirichlet allocation (LDA) [65] to accomplish topic modeling of the T documents. LDA is a generative probabilistic model that results in interpretable dimensionality reduction, which means that we reduced 41,664 terms to 45 topics for our data. A topic is a multimodal distribution of terms over an entire vocabulary (in our case, all the filtered terms). A topic consists of co-occurring terms in this corpus of T documents. Each document can have a mixture of these topics. Each topic contribution in a document is a probability (we refer to this as a document topic score); thus, the scores of all topics for a document sum to 1 (Figure 3D).

We performed topic modeling (Figure 1F,G) by applying the LDA model to the filtered document word vectors (Figure 1E) to find co-occurring terms and group them into topics.

Topic modeling resulted in a matrix of scores for each term by each topic, which we refer to as term scores (Figure 1F). An additional matrix shows the probability of fit for each topic (Figure 1G).

Figure $1 \mathrm{G}$ shows the topic document scores, and the maximum topic for each document is circled. This maximum topic is the topic that is the strongest for a document. When the maximum topic score is low, we can infer that the document fits many 
topics, which in critical care could mean that the patient has many clinical issues, some of which might be PTAEs and should be reviewed.

The maximum document topic scores distribution was plotted in the maximum topic histogram shown in Figure 3A. There were few documents in this corpus with a high maximum topic probability score (Figure 3B, right tail). Most of the documents were comprised of two or more topics (6.1 was the mean number of topics with a minimum score of $\geq 0.03$ ).

A small number of documents in the left tail of Figure $3 \mathrm{C}$ had a low $(<20 \%)$ maximum topic probability score, meaning that these documents were comprised of many topics. This was further illustrated in the inset (Figure 3D) displaying the topic distribution of a single document from this left tail, which had multiple topics. These extreme documents in the right and left tails were selected for manual review.

An important consideration for LDA is that the number of topics must be selected a priori. The results of topic modeling change depend on the number of topics assigned to a corpus - this is an iterative (hyperparameter tuning) process that requires human judgment to interpret the topics (based on the top terms in each topic) and determine which number of topics best fits the corpus. With too few topics assigned, topics are not cohesive and do not add any clarity or information to an analysis. With too many topics assigned, "incoherent" topics that do not capture terms common to the member documents proliferate; additionally, useful topics are likely split among smaller, more specific topics, although that does not limit the ability to analyze true clusters in the corpus.

Figure 3. Topic-modeling results for the transfusion case (T): (A) distribution of all maximum document topic scores for all T, (B) documents that have only one strong topic, (C) documents that have many topics, (D) all topic scores for a single document that has multiple topics, and (E) two documents with a score of 0.022 for every topic.

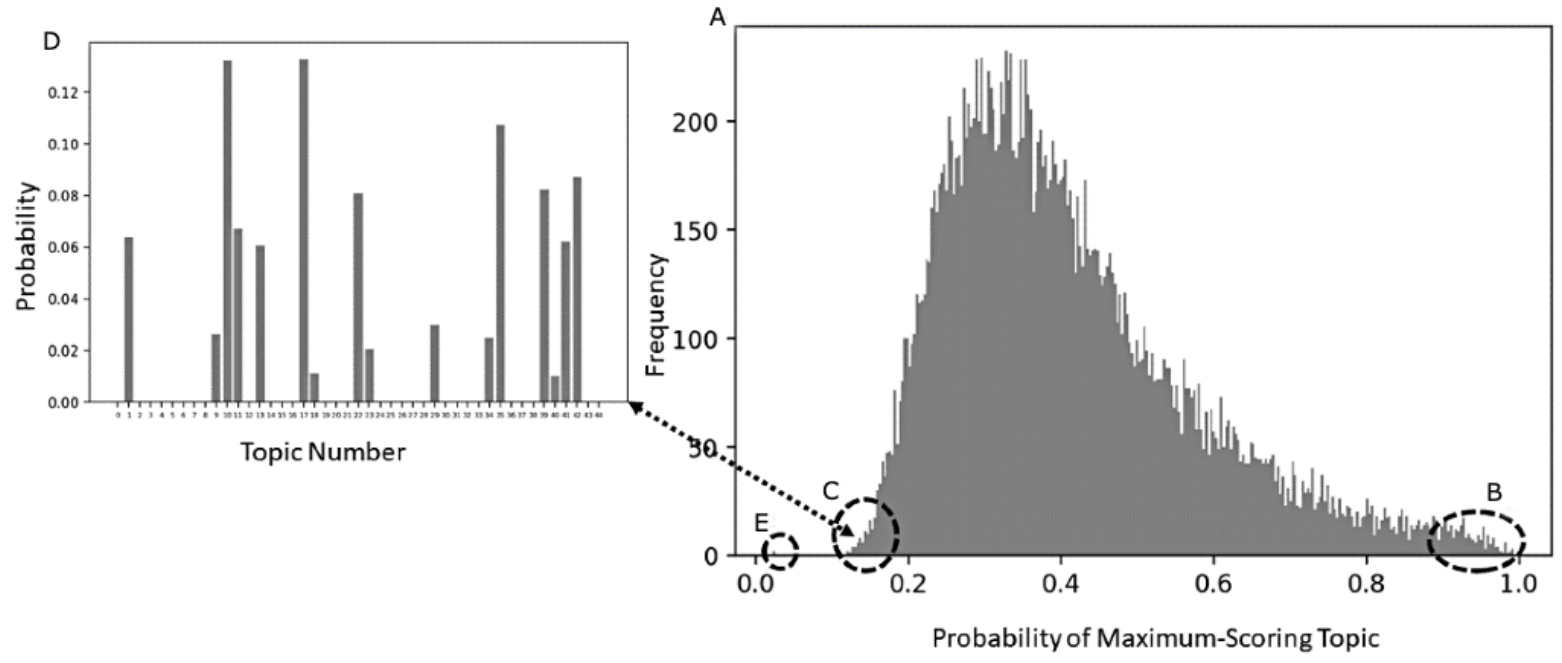

To tune the hyperparameters of the LDA model, we calculated models with the following numbers of topics: $25,35,45,55$, 65,75 , and 85 . We observed (data not shown):

- As the number of topics rose, at first, clinically meaningful topics were added. Still, at higher numbers, the additional topics were incoherent, and the large, meaningful topics tended to split in ways that were not meaningful.

- The top words in topics were generally consistent for topics that were alike across multiple topics. For example, a mechanical ventilation topic was present whether the topic number was 9,10 , or 26 .

- Although particular documents changed, the documents with high top topic scores had the top topic terms.

- Topics that had high document topic scores had overlapping concepts in the highest-scoring terms.

- Several topics were difficult to interpret and had low maximum values for both word scores and document topic scores.

- $\quad$ There were 1 to 2 dozen known TAEs $[66,67]$.

- Many documents had several topics, reflecting the clinical complexity of patients in the critical care unit [68].

\section{Transfusion Case Step 5: Review Topics}

To evaluate whether topics described PTAEs, we selected the following records for manual document review: the three top-scoring documents for each of the 45 topics (Figures $1 \mathrm{H}$ and $3 \mathrm{~A}, \mathrm{~B})$, the 7 documents with the most topics with significant scores ( $\geq 0.03$ ) (such as in Figure 3C), and 24 randomly selected documents from the $\mathrm{T}$ group. We abstracted events, observations, clinicians' attributions of causality, and clinicians' diagnoses, as well as their dates (where offered). We used further abstractions and tabulations to protect patients' confidentiality.

We tested comparisons with the Fisher exact test [69].

\section{Results}

Despite the inclusion of n-grams with a length of 1 to 5 in the vectorization, the terms that we extracted during classification were unigrams.

\section{Distribution of Transfusion Topic Document Scores}

A histogram of maximum topic scores (Figure 3A) showed the distribution of each document's maximum (strongest) topic. There were few documents in this corpus with a high maximum topic probability score (Figure 3B, right tail). The left tail of 
Figure $3 \mathrm{C}$ shows a small number of documents with a maximum topic probability score that is low, or less than $20 \%$, suggesting these documents comprised many topics. Figure 3D illustrates this with the topic distribution of a single document from this left tail. The lowest maximum topic document score was 0.022 . Two documents had topic document scores of 0.022 for every topic (Figure 3E). They each had only one short record: a brief electrocardiogram report.
There was no strict relationship between top word score and the frequency distribution of document topic scores (Figure 4). Table 1 shows the categories of maximum document topic scores per number of topics. It shows that if there is one topic, the score is over 0.50. As the number of topics increases, the maximum topic score declines. The average number of topics with a topic document score $>0.03$ was 6.1 . The maximum topic document score was 0.994 .

Figure 4. Distribution of topic document scores and top term scores for the transfusion case.

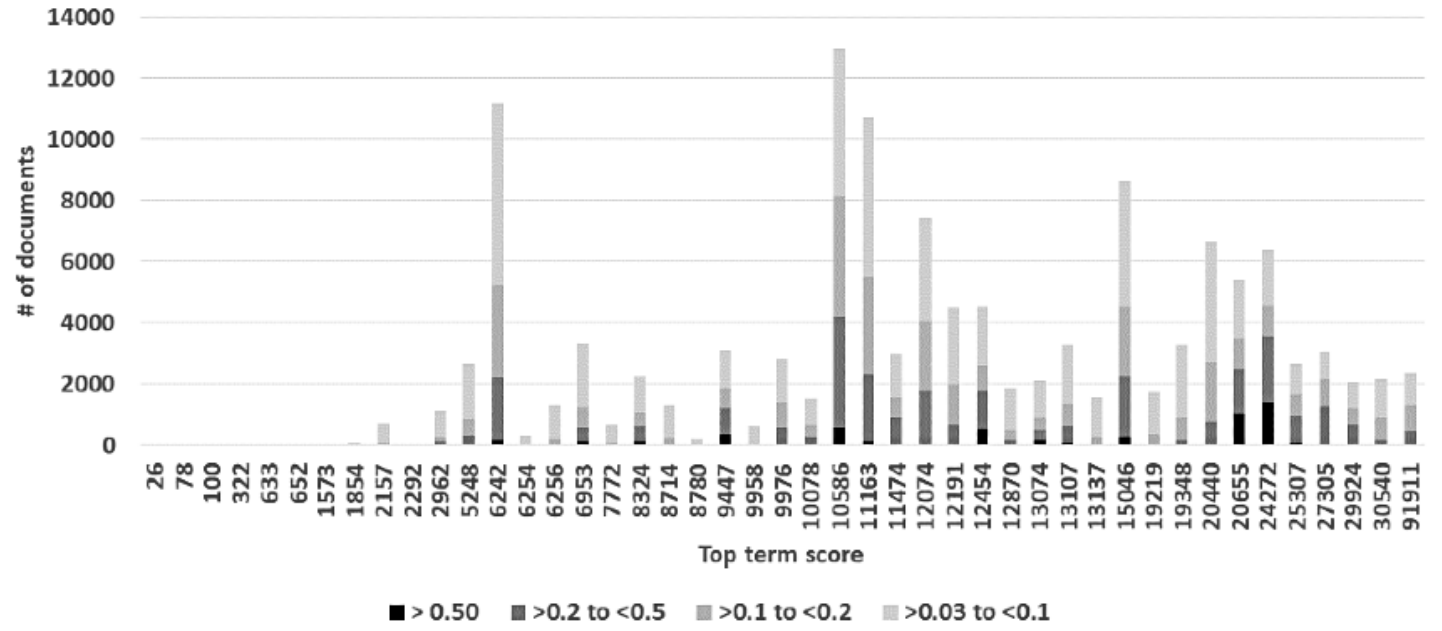

Table 1. Maximum document topic score in the transfusion case for documents in relation to number of topics in a document.

\begin{tabular}{llll}
\hline Number of document topic scores $\geq 0.03$ & Maximum document topic score, $\mathrm{n}$ & $0.1 \leq \mathrm{score}<0.2$ \\
\hline 0 & Score $\geq 0.5$ & $0.2 \leq$ score $<0.5$ & 0 \\
1 & 0 & 0 & 0 \\
2 & 132 & 0 & 0 \\
3 & 484 & 13 & 0 \\
4 & 1121 & 326 & 0 \\
5 & 1462 & 1138 & 0 \\
6 & 1179 & 2582 & 13 \\
7 & 610 & 3509 & 85 \\
8 & 209 & 3595 & 191 \\
9 & 55 & 2427 & 265 \\
10 & 13 & 1183 & 173 \\
11 & 0 & 414 & 91 \\
12 & 0 & 113 & 25 \\
13 & 0 & 25 & 5 \\
\hline
\end{tabular}

\section{Top-Scoring Documents for Each Transfusion Topic}

Table S1 (Multimedia Appendix 1) shows, for each topic, the score for the top term, the top 20 terms, the top document score, and the distribution of documents by document score range. The rows are sorted by top document score. The maximum word score ranged from 26 to 91,911 . The terms with the top 20 scores included plain English words, clinical words, acronyms, shortened words, and misspellings. The maximum document score for a topic went as high as 0.994 . The document scores were widely distributed.

Table S2 (Multimedia Appendix 1) presents the summaries of 135 documents. As is expected when hyperparameters of the model are optimal, most topics ( $n=35)$ were "coherent," meaning the top documents had clear common themes within topics 
consistent with the lists of the top 20 terms in the topic. The coherent topics had higher top document scores and tended to be the maximum-scoring topics. Among the least coherent topics, the tendency for documents was to have some other topic as the maximum-scoring topic. This is expected with LDA, as the words that do not fit into a coherent topic will be allocated to separate "junk" topics.

The tabulation of the presence or absence of the notes expected to have the most clinical information showed that 122 had a discharge summary, 66 had a nursing note, and 21 had a physician progress note. None of the documents attributed an AE to transfusion in the billing codes.

New or worsening PTAEs occurring within 1 to 2 days in the $\mathrm{T}$ group were:

- In the heart category: atrial fibrillation, tachycardia, bradycardia, other heart rhythm abnormalities, hypotension;

- In the lung category: hypoxia, mechanical ventilation, bilateral pleural effusions, pulmonary edema;

- In the volume category: edema, diuresis therapy, acute kidney failure;

- In the absence of evidence for other infections: fever or chills.

Many documents $(n=40)$ could not be evaluated for TAEs because either the transfusion dates were missing or there was no identified treatment when transfusion could be presumed. For others, there was a clear alternate reason for heart or lung problems: advanced cancer $(n=7)$, thrombotic thrombocytopenic purpura present at admission $(\mathrm{n}=1)$, liver failure $(\mathrm{n}=1)$, and lung infection $(\mathrm{n}=1)$.

Out of the remaining 85 documents with transfusion data, 52 had evidence of PTAEs; the most common were heart PTAEs $(n=35)$ and lung PTAEs $(n=33)$, while non-infection-related fever or chills $(n=12)$ and fluid overload $(n=12)$ were less common. A few documents explicitly considered transfusion as the cause of AEs: in topic 30 (blood disease), one attributed disseminated intravascular coagulation to transfusion and another listed but discarded the possibility of TRALI or TACO, a document in topic 3 (bone trauma from motor vehicle accident) proposed PTAEs, and a document in topic 40 attributed a drop in platelets to transfusion. In 2 documents, the PTAEs were attributed to contrast (topic 37, kidney failure), a brand name for metronidazole (topic 38, colon problem), and surgery (3 cases of bone trauma from a motor vehicle accident).

Documents with transfusion timing but no apparent TAE were in the following topics: 10 (one of the mechanical ventilation topics), 2 (esophageal varices banding), 7 (spine surgery), 18 (gastrointestinal bleeding), 31, and 8. For 10 documents, separate transfusion and PTAE codes were present but were not conceptually linked.

We read 24 randomly selected documents to obtain 20 that did not have advanced cancer, cirrhosis, or severe lung trauma. They are summarized at the bottom of Table S2 (Multimedia Appendix 1).

The documents in the cardiovascular topic group were more likely than the random group to have any of the heart PTAEs (proportion difference $=0.47 ; P=.02$ ). The analogous analysis for 14 documents in the lung failure topic group showed a higher rate of any lung PTAEs (proportion difference=0.37; $P=.049$ ).

Table S3 (Multimedia Appendix 1) depicts the characteristics of the 8 documents that had 13 or 14 topics. Their document topic scores were distributed across many topics, and the notes described a large number of medical challenges to the patients. All of these documents had both discharge summaries and nurse progress notes. One physician wrote that the patient developed alloantibodies and had a delayed transfusion reaction. None of the billing codes linked transfusion to an $\mathrm{AE}$, and in 2 records, the codes included an outcome code. All 8 documents provided dates of transfusion, including 3 for which cancer was the more likely cause of the AE. Of the remaining 5 documents, 3 had pulmonary PTAEs:

- The document with all three types of PTAEs had only one topic with a score above 0.1 (topic 42 , heart attack), and the notes, but not codes, indicated the patient had a delayed transfusion reaction.

- The document with pulmonary and volume PTAEs had the following topics with scores $\geq 0.1$ : topic 42 (heart attack), topic 24 (tPA [tissue plasminogen activator] to lyse thrombus), topic 10 (cirrhosis), and topic 1 (x-ray confirmation of device placement). The notes attributed worsening acute kidney failure to an antibiotic.

- The document with only pulmonary PTAEs had the following topics with scores $\geq 0.1$ : topic 24 (tPA to lyse thrombus), topic 10 (mechanical ventilation), and topic 37 (kidney failure).

\section{Discussion}

The Shakespeare method successfully identified PTAEs. The three top-scoring documents in cardiovascular topics (topic 17, heart valve repair; topic 33, tapped pericardial effusion; topic 35 , coronary artery bypass graft; topic 42 , heart attack; and topic 11, vascular repair) were associated with cardiovascular PTAEs: atrial fibrillation, tachycardia, bradycardia, other heart rhythm abnormality, or hypotension, which are features of TAEs $[66,67]$.

Mechanical ventilation and nitric oxide therapy (topics 9, 10, 16, and 26) were used to treat lung failure [70], which was also a topic (topic 29, acute respiratory distress syndrome). The associated breathing PTAE (hypoxia, mechanical ventilation, bilateral pleural effusion, and pulmonary edema) are components of TRALI and TACO $[66,67]$.

Other PTAEs that correspond with known TAEs were also observed in the top three documents of topics:

- Features of the volume overload component of TACO (edema, acute renal failure, and diuresis) [67];

- A feature of hemolytic transfusion reaction and febrile nonhemolytic transfusion reaction (fever without other signs of infection) [67].

\section{Distribution of Transfusion Topic Document Scores}

Incoherent topics had few or no documents with high topic document scores; most documents scored at or close to zero (see example in Figure 5A). A coherent topic follows a similar 
distribution, but the range is much greater, as seen in the $\mathrm{X}$-axis of Figure 5B when compared to Figure 5A. The coherent topics

received higher scores in many documents.

Figure 5. Distribution of document topic scores for two topics in the transfusion case: (a) topic 8 , a noncoherent topic, and (b) topic 42 , a coherent topic.
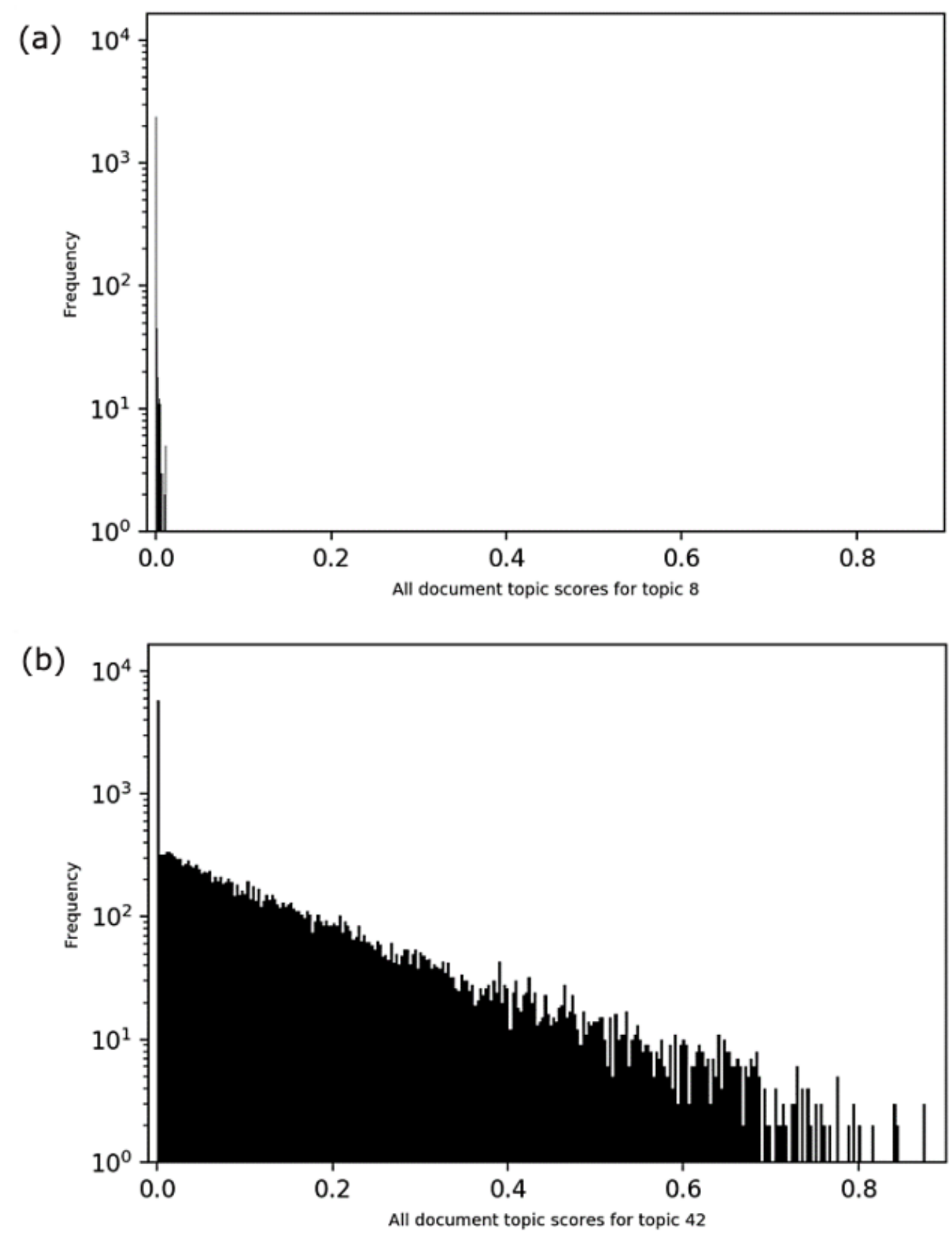

\section{Top-Scoring Documents for Each Transfusion Topic}

Many topics were conditions that can be reasons for transfusion: anemia [68]; heart attack [71]; blood disease (including blood cancers, chemotherapy, bone marrow transplant, neutropenia, thrombocytopenia, and pancytopenia) [68,72]; major surgery, vascular occlusion or repair, and gastrointestinal problems or bleeding [73]; and tPA to lyse thrombus, because antithrombotic treatment can cause bleeding [74].

Some topics could be consequences of the reasons for transfusion. Tapped pericardial effusion is a candidate because pericardial effusions can result from cancers, heart disease, aortic dissection, and other conditions [75] that prompt transfusion [76]. Past sternotomy, a consequence of heart surgery [77], is often a reason for transfusion [78]. Pneumomediastinum could be caused by surgery, or tearing of the esophagus or trachea [79], which in turn could be a reason to transfuse [73]. Skin breakdown can be a consequence of long-term bed rest $[76,80]$, which is generally associated with critical illness and anemia [68], which in turn prompts transfusion [68].

Some could be alternate reasons for a PTAE: advanced cancer [81], liver disease [82], and infection [83]. 
Others could be a PTAE or sequelae of PTAEs: mechanical ventilation, which is a known consequence of TAEs [84,85]; pneumomediastinum, which could be caused by mechanical ventilation [79]; a tracheostomy tube, which is placed when long-term mechanical ventilation is anticipated [86]; acute respiratory distress syndrome, which shares features (noncardiogenic pulmonary edema and hypoxia) with TRALI [84] and is also known as acute lung injury and is treated with noninvasive or invasive ventilation [87]; and permanent hemodialysis indicating permanent kidney injury [88], which can result from hemolytic transfusion reactions [89] and is associated with volume overload [90], which is part of TACO [66].

\section{Documents With Multiple Transfusion Topics}

The high number of topics per document reflects the complexity of patients in the critical care unit. Multiple topics covering illnesses and procedures were expected for critically ill patients and were the norm for the vast majority of documents. The documents with 13 and 14 significant topics described many complex clinical problems consistent with the need for critical care. Several of the documents had a variety of PTAEs in more than one category, suggesting the importance of checking the documents with multiple nontrivial topics for PTAEs.

\section{The Time-Based Case}

\section{Introduction and Study Objective}

We wanted to simulate real-time analysis to find new or increasing events in the most recent time period. We examined whether the Shakespeare method would overcome the challenges of EHR texts to detect not only clinical and administrative changes but also trending PAEs, including those related to heparin contamination, which were first reported early in 2008 [91]. Heparin is an anticoagulant used in surgeries [91].

\section{Methods}

The MIMIC-III EHRs for critical care admissions used one medical record system from 2001 to 2008 and another system post-2008. We received the real dates, within several weeks, for the earlier data. We followed the same step 1 (create n-gram vectors) as described in The Shakespeare Method subsection of the General Methods section.

\section{Time-Based Case Step 2: Create Groups}

We then divided the study population into three cohorts: admissions starting between July 1, 2001, and June 30, 2006 (period 1; 14,410 documents); July 1, 2006, to June 30, 2007 (period 2; 3581 documents), and July 1, 2007, to June 30, 2008 (period 3; 3296 documents).

\section{Time-Based Case Step 3: Extract Significant Target Terms}

To focus on new or increasing AEs, we reduced the number of words to analyze by filtering by whether they were unusual and increasing (or new) in period 3 compared to period 2 (Figures 1C,D and 6A). We adopted two parallel approaches, as shown in Figure 6: (1) binary classification of the notes and (2) analysis of term frequency between periods 3 and 2 .

For the binary classification, we fit two classification models: LR with L2/ridge regularization [61] and multinomial NB $[59,60]$. Model evaluation found LR outperformed NB (with a weighted average F1 score of 0.76 compared to NB's weighted average F1 of 0.69 ), but that NB more effectively identified completely new terms in the target time period.

After evaluating the models, we refit both models without a train-test split on the entire 24-month data set and combined the top 5000 features from LR (those with the highest positive coefficient associated with the positive target class) and the top 5000 features from NB (those with the lowest log probability ratio). Combining the lists resulted in a set of 9896 terms.

We used frequency analysis to find emerging rare clinical events. We identified two groups of terms: (1) those which appeared in fewer than $10 \%$ of documents in period 2 and saw a $30 \%$ increase in raw frequency in period 3, and (2) any terms that never appeared in period 2 and did appear in period 3 . For those new terms appearing in period 3, we filtered out digit-only terms (a large number of terms in this group).

For the final feature set, we took the intersection of terms identified from the binary classification and frequency analysis processes. This resulted in 6122 significant terms identified from the initial 117,049 unique terms in the documents from period $3(5.2 \%$ of terms). We revectorized (Figure 1E) the 12-month corpus from period 3 using the combined feature list as our vocabulary (which has the effect of filtering the notes to only include terms in the vocabulary). 
Figure 6. Feature extraction flowchart for the time-based case. This demonstrates the two parallel processes for extracting relevant features prior to topic modeling on the notes: term frequency analysis and binary classification of notes.

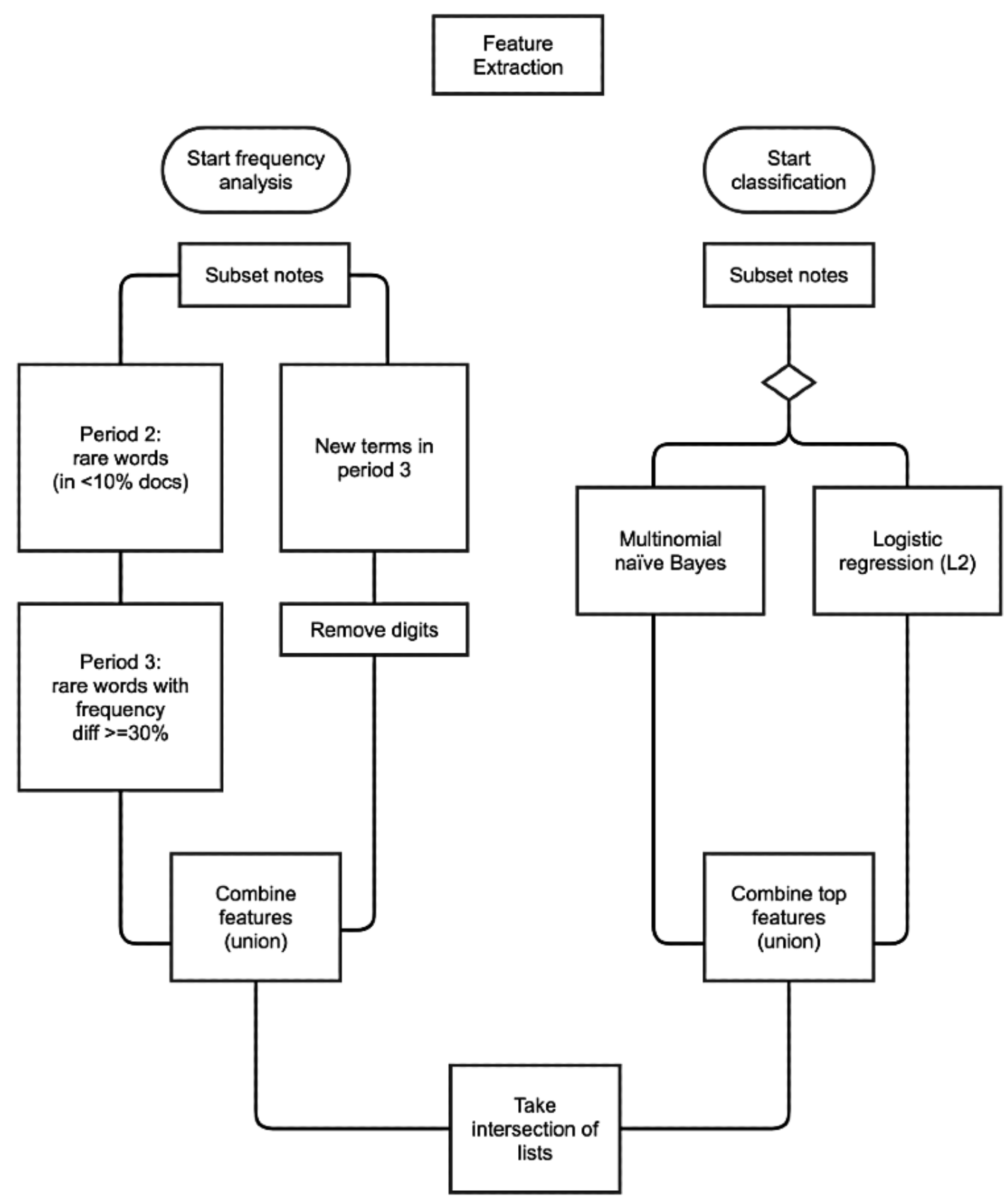

\section{Time-Based Case Step 4: Model Topics}

The co-occurrence of words in documents in the last time period was analyzed with LDA topic analysis [65]. We chose the final number of topics $(\mathrm{n}=20)$ based on a balance of large and small topics and at least one topic with no substantive words. We used the words with the highest scores of their relationship to topics (Figure 1F), as well as the topic document scores that indicate the probability of the topic fit for a document (Figure 1G), to explore topic meanings. We manually read the three top-scoring documents for each topic (Figure 1H).

\section{Time-Based Case Step 5: Review Topics}

Documents from selected individual admissions, as well as summary data from July 2001 to June 2008, were used to evaluate whether any topics formed around AEs. Most topics inspired time plots of selected words, diagnosis codes, or procedure codes (see criteria in Table S4, Multimedia Appendix 1) through periods 1,2 , and 3 . Slopes were analyzed for changes $[92,93]$.

For this report, out of concern for patient privacy, we substituted generic words (such as "condition01," "condition02," etc) for rare conditions, drugs, events, and languages since the year of admission is being presented. Related substitute words (eg, "condition09a," "condition09b") were used as synonyms.

\section{Results}

Table 2 shows the statistics for each topic. The strength of the maximum word score in a topic roughly corresponded with the number of admissions that had strong matches with the topic. The words in many of the topics seem to readily suggest 
interpretations, for example, long complex stay (topic 18), heart problem (topic 3), trauma (topic 19), cardiac catheterization (topic 7), brain (topic 1), cardiac catheterization (topic 17), abdomen (topic 12), uterus (topic 16), and a foreign language (topic 2). The other topics were deemed broad.

Table 2. The score for the top term, top 20 substantive terms, top document score, and distribution of documents by document score range for each topic in the time-based case. "Substantive" terms had topic scores above the minimum topic score.

\begin{tabular}{|c|c|c|c|c|c|c|c|c|}
\hline \multirow[t]{2}{*}{ Topic \# } & \multirow{2}{*}{$\begin{array}{l}\text { Top term } \\
\text { score }\end{array}$} & \multirow[t]{2}{*}{ Top 20 substantive terms } & \multirow{2}{*}{$\begin{array}{l}\text { Top docu- } \\
\text { ment score }\end{array}$} & \multicolumn{5}{|c|}{ Documents in topic score range, $n$} \\
\hline & & & & $\geq 0.03$ & $\geq 0.5$ & $\begin{array}{l}\geq 0.2 \text { to } \\
<0.5\end{array}$ & $\begin{array}{l}\geq 0.1 \text { to } \\
<0.2\end{array}$ & $\begin{array}{l}\geq 0.03 \text { to } \\
<0.1\end{array}$ \\
\hline 18 & 75,372 & $\begin{array}{l}\text { for, hr, plan, vent, intubated, cont, today, skin, are, } \\
\text { family, per, support, increased, off, goal, iv, placed, } \\
\text { trach, foley, pain }\end{array}$ & 0.99 & 1793 & 505 & 623 & 326 & 339 \\
\hline 3 & 42,070 & $\begin{array}{l}\text { for, hr, pain, bp, are, you, iv, family, time, ccu, per, } \\
\text { sats, note, heart, micu, received, skin, if, acute, plan }\end{array}$ & 1.0 & 2224 & 912 & 697 & 328 & 287 \\
\hline 19 & 39,731 & $\begin{array}{l}\text { for, are, pain, you, comparison, acute, upper, evaluate, } \\
\text { iv, trauma, hospital, if, note, time, large, level, pleural, } \\
\text { wbc, read, throughout }\end{array}$ & 1.0 & 2089 & 355 & 880 & 468 & 386 \\
\hline 7 & 30,722 & $\begin{array}{l}\text { for, are, pain, pleural, cabg, hr, plan, per, comparison, } \\
\text { off, bp, pericardial, time, neo, iv, heart, md, mm, mr, } \\
\text { catheter }\end{array}$ & 1.0 & 1686 & 589 & 321 & 319 & 457 \\
\hline 1 & 12,352 & $\begin{array}{l}\text { for, are, family, subarachnoid, mm, comparison, pain, } \\
\text { iv, occipital, sdh, large, evaluate, plan, cont, acute, } \\
\text { craniotomy, per, hr, note, goal }\end{array}$ & 1.0 & 749 & 181 & 235 & 118 & 215 \\
\hline 4 & 3523 & $\begin{array}{l}\text { catheter, pleural, for, pain, jp, [pain-reliever], placed, } \\
\text { large, into, pigtail, hr, cont, french, increased, are, } \\
\text { pseudoaneurysm, upper, skin, iv, comparison }\end{array}$ & 0.54 & 683 & 1 & 75 & 180 & 427 \\
\hline 17 & 3462 & $\begin{array}{l}\text { for, are, mca, into, time, catheter, arteriogram, occlu- } \\
\text { sion, mm, acute, french, ica, iv, placed, territory, large, } \\
\text { cont, comparison, goal, family }\end{array}$ & 0.77 & 534 & 39 & 99 & 127 & 269 \\
\hline 12 & 216 & $\begin{array}{l}\text { [condition01], section, gynecology, [condition02], } \\
\text { dystrophy, cesarean, [anti-thyroid], transabdominal, } \\
\text { [event01], lmp, wk, [procedure01], [progesterone], } \\
\text { prenatal, [condition03], [condition04], [antispasmodic], } \\
\text { enteropathy, [condition05], [condition06] }\end{array}$ & 0.22 & 31 & 0 & 1 & 7 & 23 \\
\hline 11 & 75 & $\begin{array}{l}\text { pentobarb, pentobarbital, cmv, encasement, prison, } \\
\text { [condition07], satellite, hematologic, rent, [condi- } \\
\text { tion08], [condition09a], [condition09b], [antibiotic], } \\
\text { federal, bleach, [device01], allergic, [rare-word01], } \\
\text { cluster, [rare-word02] }\end{array}$ & 0.11 & 26 & 0 & 0 & 1 & 25 \\
\hline 5 & 63 & [rare words, misspelled words] & 0.05 & 1 & 0 & 0 & 0 & 1 \\
\hline 15 & 36 & [rare words, misspelled words] & 0.13 & 2 & 0 & 0 & 2 & 0 \\
\hline 16 & 15 & [rare words, misspelled words] & 0.11 & 2 & 0 & 0 & 1 & 1 \\
\hline 6 & 14 & [rare words, misspelled words] & 0.02 & 0 & 0 & 0 & 0 & 0 \\
\hline 10 & 11 & [rare words, misspelled words] & 0.06 & 2 & 0 & 0 & 0 & 2 \\
\hline 0 & 10 & [rare word] & 0.04 & 1 & 0 & 0 & 0 & 1 \\
\hline 2 & 9 & [rare words, foreign language words, misspelled words] & 0.12 & 3 & 0 & 0 & 1 & 2 \\
\hline 14 & 8 & [rare words, misspelled words] & 0.03 & 1 & 0 & 0 & 0 & 1 \\
\hline 9 & 7 & [rare words, misspelled words] & 0.07 & 2 & 0 & 0 & 0 & 2 \\
\hline 13 & 6 & [rare words, misspelled words] & 0.06 & 3 & 0 & 0 & 0 & 3 \\
\hline 8 & 0 & $\ldots^{\mathrm{a}}$ & 0 & 0 & 0 & 0 & 0 & 0 \\
\hline
\end{tabular}

${ }^{\mathrm{a}}$ Not applicable. 


\section{Common Topics for the Time-Based Case}

For the most common topics, the admissions with the top three topic match scores are summarized in Table S5 (Multimedia Appendix 1). For the topics with words that suggested an interpretation, the records supported the interpretations. For the other topics, the records suggested interpretations that were consistent with the top words. Each of the three top-scoring admissions within a topic were quite similar to each other (an indication that the topics were coherent and the model was working correctly, with the exception of the third admission in topic 3).

The three top-scoring documents for topic 18 described long complex stays, which included large numbers of notes. The general words in the topic ("for," "hr," "plan," "cont," "today," "skin," and "are") were nearly ubiquitous in periods 2 and 3. The words indicating mechanical ventilation ("vent," "intubated," and "trach") were present in between 51\% and 58\% of the admissions per quarter in periods 2 and 3, with a slight, clinically insignificant increase for period 3 . The lengths of stay and numbers of notes also did not vary between periods 2 and 3.

We noticed that among the five records in Table S5 (Multimedia Appendix 1) that mentioned cardiac catheterization, all mentioned explicit or implied dosing with heparin followed the same day with hypotension that required treatment (heparin is generally part of cardiovascular procedures) [94].

Topics 3 and 7 both have cardiac catheterization for heart problems in common; for 5 out of 6 instances, the procedure or heparin administration was followed by hypotension (4 instances) that needed to be treated or heart rhythm deterioration (1 instance). To investigate whether these potential heparin AEs were increasing between July 2001 and June 2008, we plotted two measures of exposure (an invasive cardiac procedure code and "heparin") and a measure of AE ("hypotension"). The proportion of admissions that had invasive cardiovascular procedure codes (Figure 7A,B) declined overall (Figure 7A), but had a local increase in period 3 compared to period 2 . In contrast to the procedures, the words "heparin" and "hypotension" showed an overall rough increase over the entire time frame. We also noticed that the proportion of admissions with invasive cardiology codes that had the word "hypotension" increased gradually over time (Figures 7A,B), followed by a drop in the last quarter; the pattern was similar and weaker for the proportion of admissions with "heparin" that also had "hypotension." There was a decrease in "hypotension" in the last quarter, both as a proportion of all admissions, and as a proportion of either indicator of having been exposed to heparin. 
Figure 7. Heparin and hypotension for the time-based case (see Table S4 [Multimedia Appendix 1] for search criteria details). (A) Invasive cardiology-, heparin-, and hypotension-related criteria as a proportion of all admissions. Invasive cardiology is presumed to involve heparin treatment. For invasive cardiovascular procedure code, slope $=-0.0053(95 \% \mathrm{CI}-0.0069$ to -0.0037$), P<.001$; for heparin word, slope $=0.0039(95 \% \mathrm{CI} 0.0025-0.0054), P<.001$; and for hypotension word, slope $=0.0029$ (95\% CI 0.0017-0.0040), $P<.001$. (B) The word "hypotension" as a proportion of presumed heparin exposure. For the proportion of any invasive cardiovascular procedure code (presumed to involve heparin), slope $=0.0055$ (95\% CI 0.0038-0.0072), $P<.001$. For the proportion of those with "heparin," slope $=0.0013$ (95\% CI -0.00036 to 0.0030$), P=.12$.
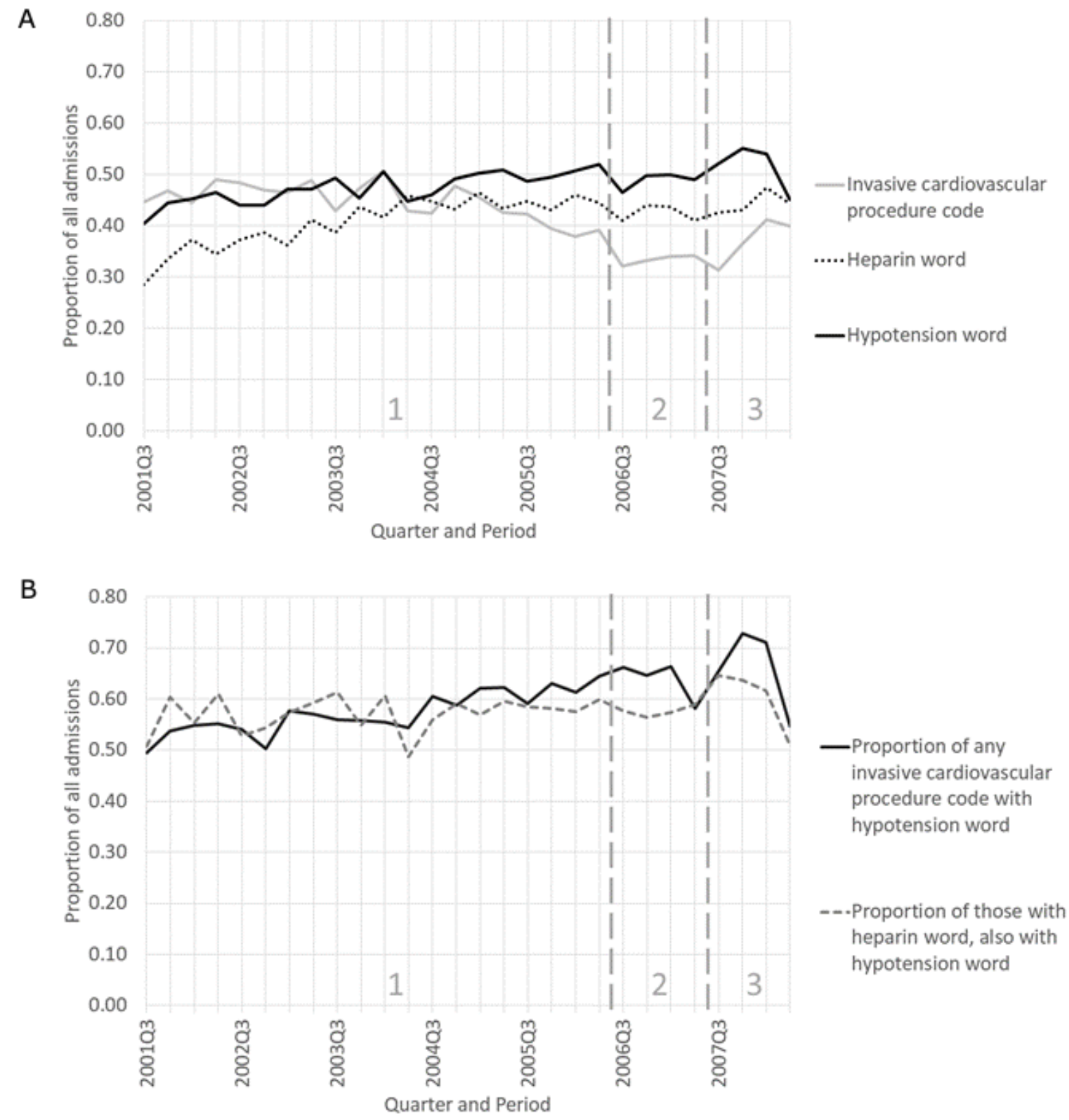

\section{Other Common Topics for the Time-Based Case}

Topic 19 (and 13) corresponded with trauma. Figure 8 shows that trauma diagnosis and procedure codes increased steadily over time through periods 1 to 3 .

The brain topic (1 and 17, combined) was centered around admissions for brain injury (ie, bleeding, ischemia, or trauma). Figure 9A-C shows that there were local increases in codes for bleeding and ischemia for period 3 compared to period 2 . There were slight increases in the codes for all three types of brain injuries overall. The text words indicating these conditions showed similar trends.
Topic 4 describes prolonged drainage after abdominal surgery. The index surgeries were performed before admission for 2 instances and during hospitalization for the third. Figure 10 shows that codes for wounds were quite infrequent. However, long patient stays with words for leaky surgical wound or catheter were more common, rose gradually over time, and had a local increase in period 3, compared to period 2.

Condition01 was the subject of the three admissions with the top match scores for topic 12. The codes and words were generally rare for the three periods and showed a local increase between periods 2 and 3 . 
Figure 8. Trauma code, word, or both as a proportion of all admissions by quarter for the time-based case (see Table S4 [Multimedia Appendix 1] for search criteria details). For the proportion of trauma code, slope $=0.0022$ (95\% CI 0.0014-0.0030), $P<.001$. For the proportion of the word "trauma," slope $=0.0057$ (95\% CI 0.0047-0.0067), $P<.001$. For the proportion with both trauma code and word, slope $=0.0019$ (95\% CI 0.0012-0.0027), $P<.001$.

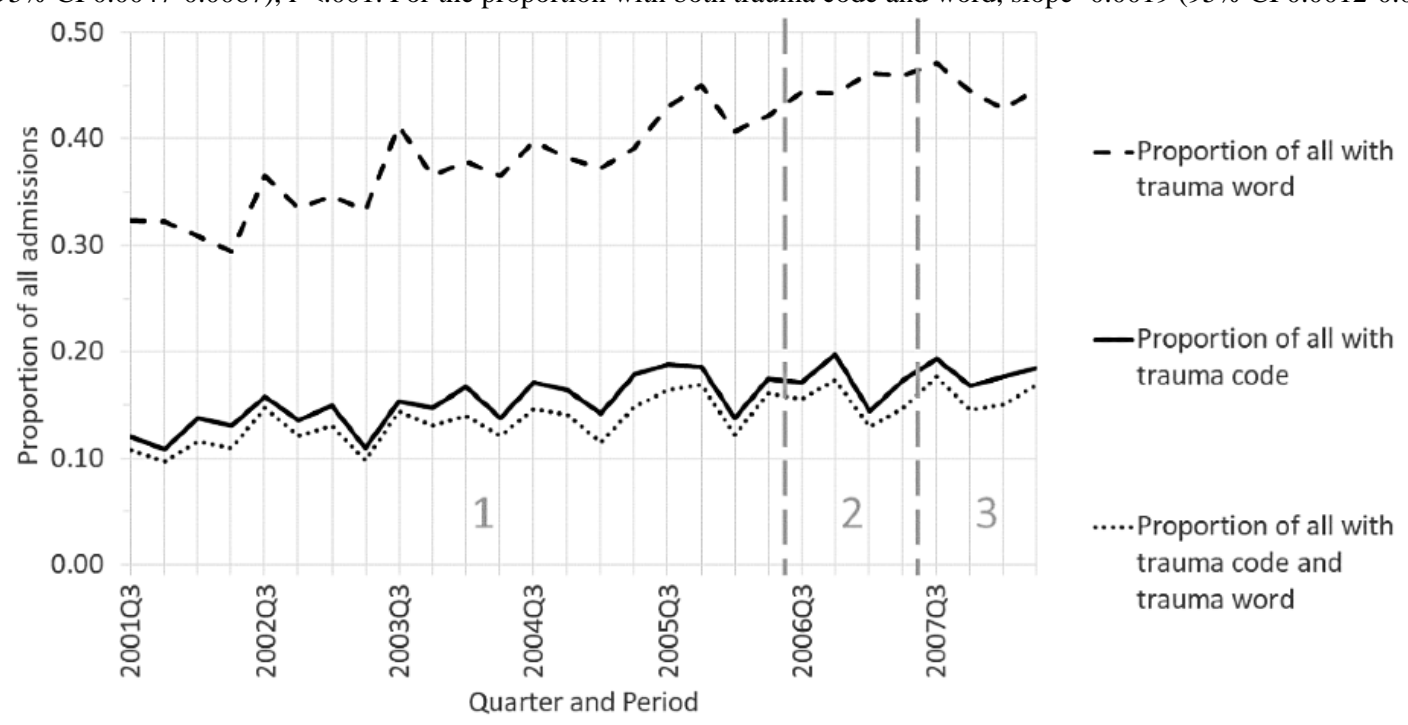


Figure 9. Brain ischemia codes or text words for (A) bleeding, (B) ischemia, and (C) trauma, as a proportion of all admissions by quarter for the time-based case (see Table S4 [Multimedia Appendix 1] for search criteria details). For brain bleed code, slope $=0.00022$ (95\% CI -0.0006 to 0.0010 ), $P=.61$. For brain word and brain bleed word, slope $=0.00039$ (95\% CI 0-0.00085), $P=.10$. For brain ischemia code, slope $=0.00019$ (95\% CI 0.00051-0.0013), $P<.001$. For brain word and "occlusion*," slope $=0$ (95\% CI -0.00064 to 0.00080$), P=.84$. For brain trauma code, slope $=0.0013$ (95\% CI $0.00073-0.0018)$, $P<.001$. For brain word and "trauma," slope=0.0021 (95\% CI 0.0014-0.0028), $P<.001$.

A

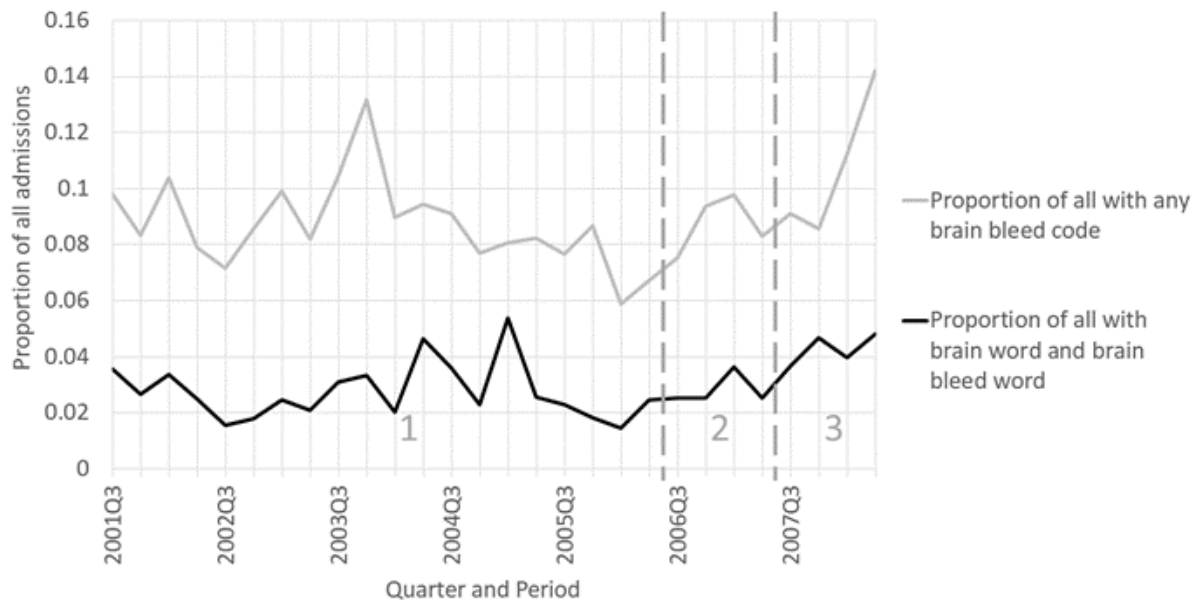

B

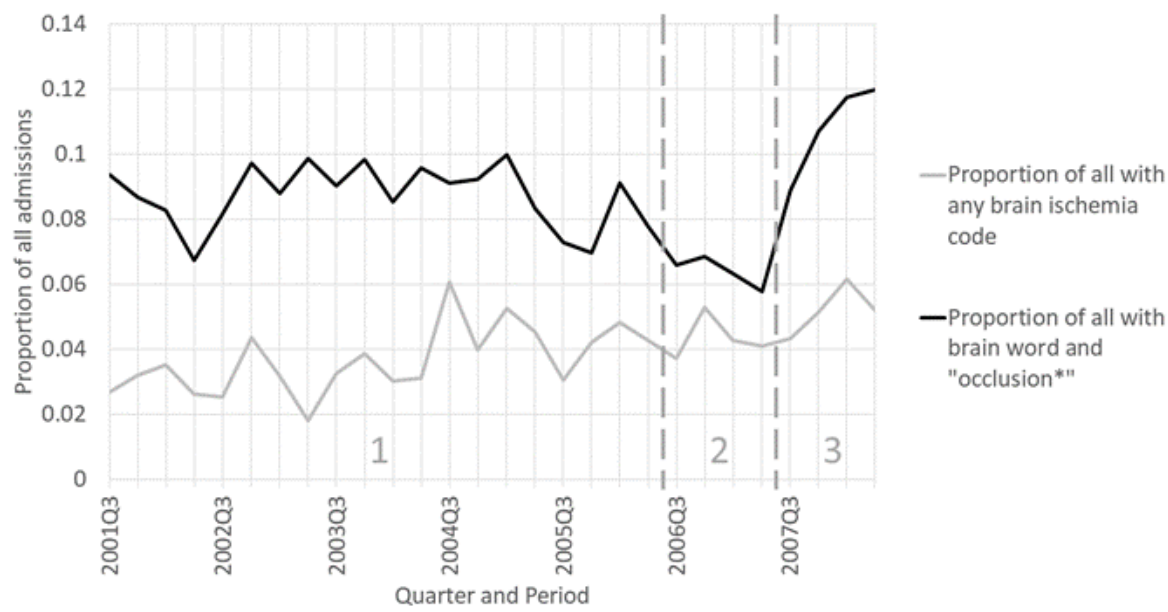

C

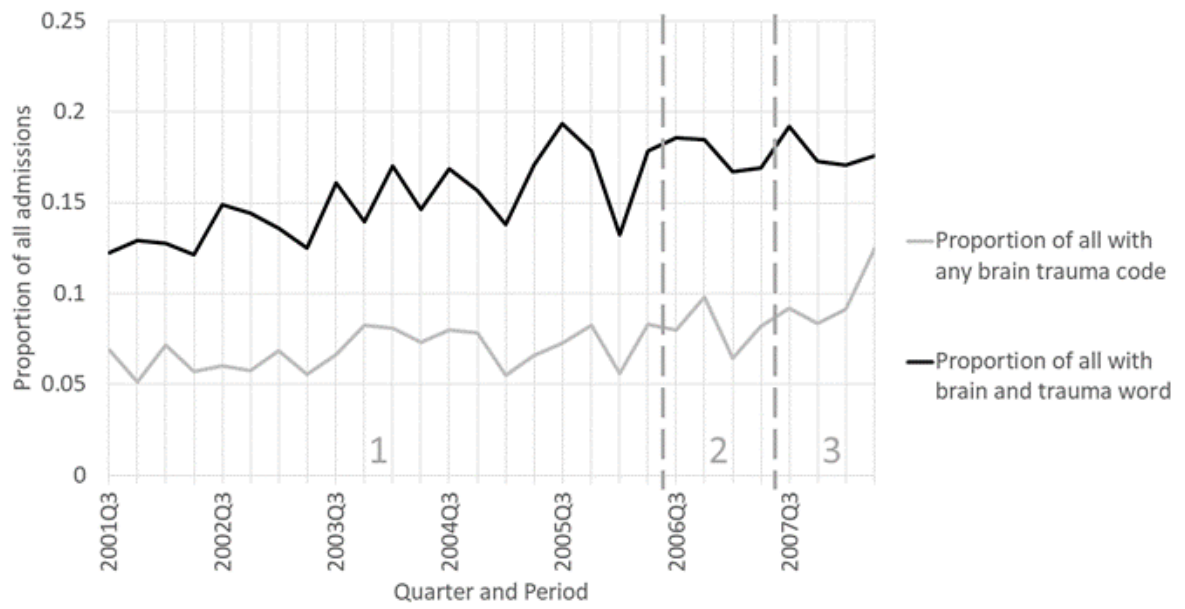


Figure 10. Excess draining from postsurgical wounds as a proportion of all admissions by quarter for the time-based case (see Table S4 [Multimedia Appendix 1] for search criteria details). For leaky surgical wound code, slope $=0.000027$ ( $95 \% \mathrm{CI}-0.000028$ to 0.000082 ), $P=.34$. For leaky surgical wound word and long stay, slope $=0.0018$ (95\% CI 0.0012-0.0024), $P<.001$. For wound catheter word and long stay, slope $=0.00038(95 \% \mathrm{CI}-0.00039$ to 0.0012$), P=.34$. For leaky surgical wound word and wound catheter word and long stay, slope $=0.0011$ (95\% CI $0.00071-0.0016), P<.001$.

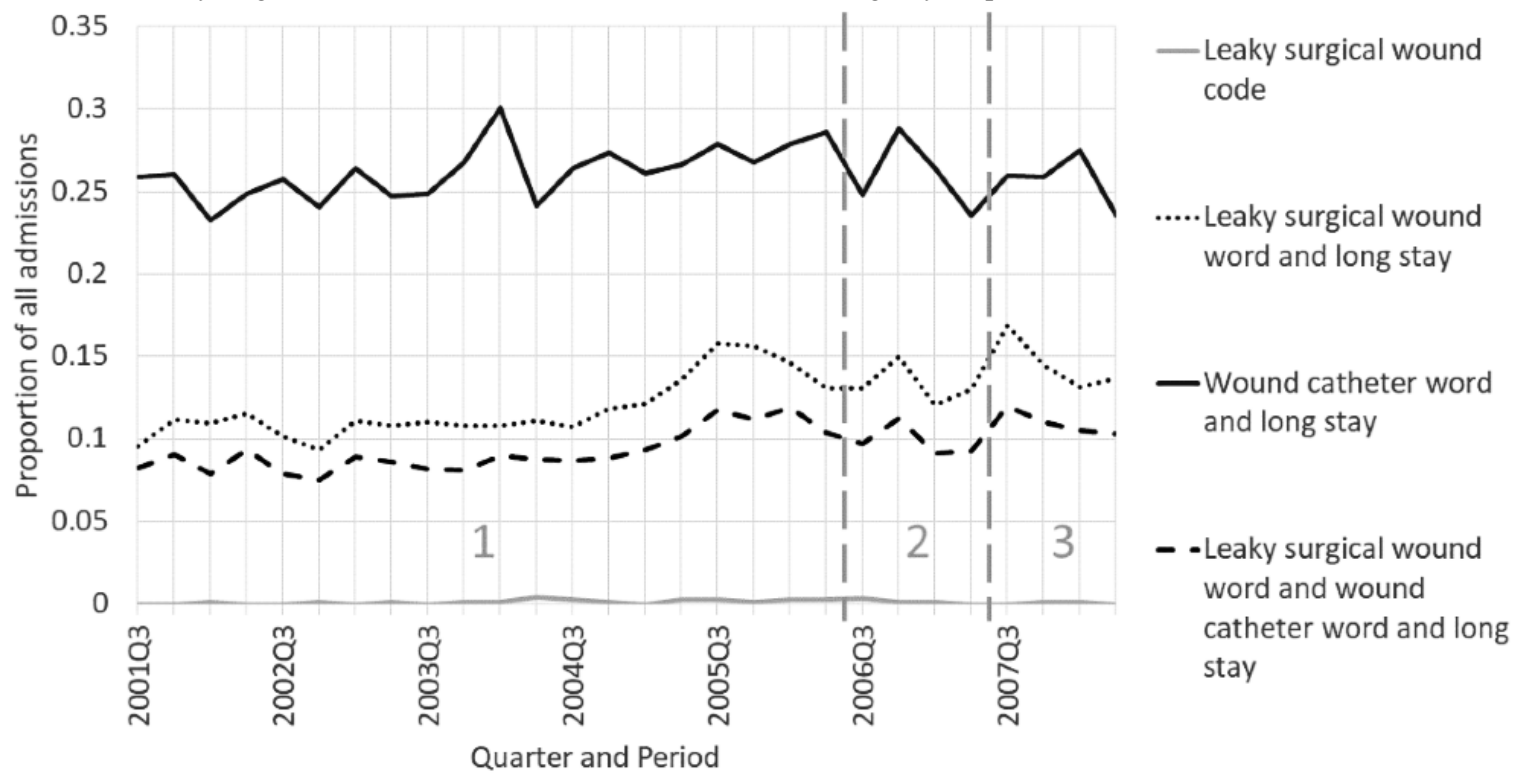

\section{Less Common Topics for the Time-Based Case}

Summaries of admissions with topic matching scores for the less common topics are shown in Table S6 (Multimedia Appendix 1). We examined the top-scoring admissions matched to topic 11 and all admissions matched to the others. All admissions in this table had topic match scores for the index topic of $<0.15$ (column 2). Despite each admission in Table S6 (Multimedia Appendix 1) having at least one strong topic match score for at least one of the strong topics in Table S5 (Multimedia Appendix 1), the topics in Table S6 are distinct from those in Table S5. Some of the topics have admissions that have common aspects (topics 11, 10, 2, 9).

A total of 14 PAEs evident in the notes were distributed among the less common topics: 13 related to medical therapy (6 medications, 3 medical devices, 2 procedures, and 2 combinations) and 2 were nonmedical. Five drug and all of the medical device PAEs were published in the product labels and/or in the medical literature. Of the PAEs, 9 occurred outside the hospital and were related to the reason for admission. The diagnosis and procedure codes generally did not give enough information to understand the specific cause and associated PAE. Figure 11 shows that while the proportions over the 7 years of admissions with allergy and anaphylaxis words steadily decreased, the diagnosis codes for drug AEs and for surgical or procedure-related AEs increased slightly over time.

The other rare and infrequent terms, related diagnosis or procedure codes, and foreign language sentences were rare throughout all three time periods and increased during period 3. 
Figure 11. Allergy, anaphylaxis, and adverse effect (AE) as a proportion of admissions by quarter for the time-based case (see Table S4 [Multimedia Appendix 1] for search criteria details). For allergy or anaphylaxis word, slope $=-0.0022$ ( $95 \%$ CI -0.0027 to -0.0018 ), $P<.001$. For drug AE code, slope $=0.00031(95 \% \mathrm{CI}-0.000079$ to 0.00070$), P=.12$. For surgery or medical AE code, slope $=0.00049(95 \% \mathrm{CI}-0.00022$ to 0.0012$), P=.18$.

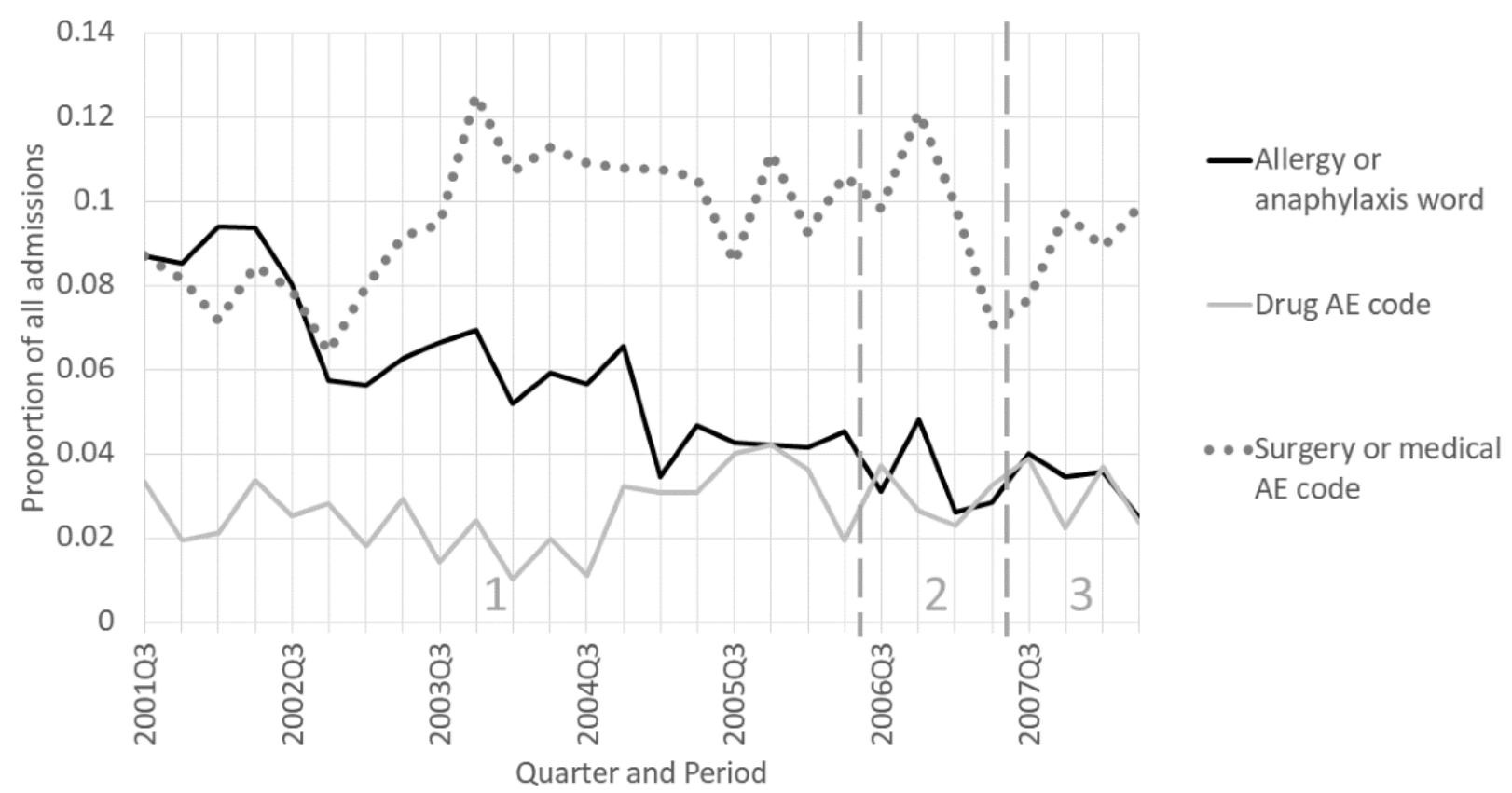

\section{Discussion}

We succeeded in our expectation of finding increases in clinical events and our hope of finding increases in PAEs, especially PAEs that were not attributed and thus likely not reported. We found increases in hypotension following heparin or presumed heparin exposure. Hypotension occurring in the cardiac catheterization lab could be a vasovagal reaction [95]. However, vasovagal reaction generally does not respond to fluids and drugs for raising blood pressure, and hypotension in all our observed patients did respond to treatment. Hypotension can occur as anaphylaxis begins and, alone, may reflect mild anaphylaxis. We note that the nurses and physicians that described the sequence of events did not link sudden hypotension to heparin and the diagnosis codes did not reflect any awareness of a link. The warnings from the FDA and the Centers for Disease Control and Prevention about heparin in the winter of 2007-2008 were for anaphylaxis due to contaminated heparin $[96,97]$. Knowledge of the extent of the distribution of contaminated heparin products was not specific, so it may have been in the hospital's stock at the time. We had expected to see increases starting in 2006 because a few articles indicate heparin may have been adulterated before 2007 [98-100], but were surprised that the increases had started before 2006. The reduction in the last quarter coincided with recalls of contaminated heparin products and lend credibility to the idea that contaminated heparin was in slowly increasing use at this hospital for many years. It is surprising that such a high proportion of the invasive cardiac catheter patients in the last 2 years experienced hypotension following heparin exposure (either as explicitly documented administration or implicitly in the catheter coating).

Other types of clinical event changes we detected from periods 2 to 3 were increases in patients with common conditions (heart disease, brain injuries, trauma, and complex conditions associated with long hospital stays), increases in rare conditions, change in administration (foreign language portion), and PAEs of concern. The increases in common conditions may have reflected hospital marketing [101]. The increases in rare conditions could have reflected chance, or marketing as a referral center.

Nine of the PAEs happened outside the hospital and illustrate the utility of hospital records for monitoring severe reactions that occur in other health facilities or outside the health care system. Our method was useful for detecting words that are rare in hospital records, partly reflecting events that normally occur outside the hospital.

The topic with the highest document score exhibited behavior typical of a topic containing words that are common to most documents. The filter that was removing words comprised of only digits also removed digits from some words. This resulted in some high-frequency words entering the vocabulary. When topic modeling, this resulted in high scores for these common words in the topics where they were correlated (as expected, this happened in several topics) and created a common word topic (topic 18). This topic is a noise topic; the LDA model will put words that are low scoring and not correlated with other topics into their own noise topic in order to deal with noise and frequent words. Because this topic included words that were frequent in almost all documents, the document topic scores for this topic were high as expected [102]. This was dealt with by looking at the other more coherent topics that were assigned to each document (essentially ignoring this common-noise topic), capturing what most documents had in common. The top-scoring words in this topic that were general survived the ensemble filtering method as an artifact of the digit-removal step. For future work, we recommend removing this step from the filtering 
process and relying on the classification terms to filter out irrelevant variations of terms.

Our method worked despite:

- The known challenges posed by clinical text notes;

- Restriction to one major hospital;

- Lack of all surgical and non-critical care unit nursing notes, and variable lack of physician, nursing, or discharge summary notes, probably reflecting the hospital policy of gradually converting types of notes to EHRs [103];

- Errors up to several weeks in dates.

Different, and hopefully improved, results may be derived from EHR databases that are more complete and have actual dates.

\section{Discussion of the Shakespeare Method}

\section{Comparison of the Shakespeare Method to Other Applications of LDA Topic Modeling}

LDA topic modeling has been used for a variety of NLP tasks $[63,64]$ (although it can also be used on other high-dimension data) such as text classification and filtering [65]. LDA topic modeling has been applied to the unstructured notes of EHRs to describe clinical groups [104-108] and predicting outcomes [109-116]. We were unable to find published instances of LDA topic-modeling applications for AE detection. Furthermore, we found none that apply LDA topic modeling to words or phrases in documents in the group of interest that are filtered to terms that most significantly distinguished a patient group of interest from a comparison group. This filtering process was essential for identifying topics describing the unique qualities of target versus comparison groups. Additionally, to our knowledge, we were the first to check the interpretation of documents with large numbers of topics with nontrivial scores.

The chosen number of topics was effective for identifying a range of PAEs. Evaluation of the overlap of topics and contents of documents identified for the varying numbers of topics has not been reported in the literature. Our iterative approach to evaluating different hyperparameters demonstrated, to our satisfaction, the relative stability of PAEs indicated by topics.

We determined the number of topics based on our experience of tuning the hyperparameters, the number of AEs reported in the literature, and the complexities of critical care patients. We were satisfied with the number because there was both overlap of topics that simultaneously had high word and document scores and some incoherent topics with low scores. As the number of topics becomes too large, additional topics are uninterpretable, and that as data set size increases, more robust topics are generated [117]. A systematic evaluation of the number of topics and other hyperparameters is always necessary for LDA topic modeling in a new setting.

LDA topic modeling has enabled identifying records for specific patients [118] who are or were clinically similar to an index patient. Identification of specific admissions is crucial to investigate PAEs. As reported in other studies [104], the topics with high scores tended to have good overlap of documents with similar clinical course and PAEs. Minor adjustments to the number of topics would still result in identifying the same PAE, even if different documents receive the top scores.

In the setting of using EHR notes with topic modeling to predict an outcome, studies noted that bigrams, trigrams, and unusual words added predictive ability [104,109]. Only unigrams survived our filtering process; however, different use cases or hyperparameter settings could yield useful multiword n-grams.

\section{Use of Classification to Filter Document Vectors}

As noted before in the transfusion case, we were initially surprised that primarily unigrams (and not the longer sequences) appeared to play a significant role in distinguishing transfusion from comparison texts. We believe it is possible that enough unigrams that were part of meaningful phrases were also in other phrases or were significant on their own to result in relatively higher scores. For example, although "mechanical ventilation" conveys more meaning than just "mechanical" or "ventilation," each word occurs singly or in phrases other than "mechanical ventilation." We observed in the time-based case that similarly only unigrams survived classification.

Because bigrams and phrases were important in other LDA studies $[104,109]$, we do not conclude that our unigram finding is necessarily applicable to other study settings. In this data set and blood transfusion and time-based cases, including only unigrams would not be expected to have changed the particular unigrams selected during the ensemble classification step. In other studies, it might be important to include n-grams where $\mathrm{n}>1$.

Filtering the vectors to only terms that were important for focusing the topics on clinical conditions specific to the index condition, including reasons for and consequences of the condition, was important for identifying PAEs.

\section{Unsupervised Methods for the Surveillance of AEs in EHRs}

We observed that the notes contained much more AE data than explicit discussion. We also found more AE data in the notes than in the diagnosis and procedure codes. Our prior analysis of diagnosis codes [57] demonstrated that in transfused versus nontransfused patients, there were some explicit TAEs, as well as more frequent diagnoses that were similar to TAEs (TRALI vs breathing difficulty, TACO vs acute kidney failure, etc). None of the documents we manually reviewed for this transfusion study bore any explicit TAE diagnosis code. Our prior and current analyses demonstrate that effective surveillance could benefit from using unstructured text as well as codes.

Our method was successful despite the limitations of this data set. The extent of records for each admission grew during the time that the data were collected because of the hospital's policy of gradually adding more types of records to EHRs [103]. There was variation in the presence of nursing and physician progress notes in the examined records, which would not be present in the EHRs in systems that have long since become completely electronic. The presence of different types of records would logically have influenced the generated topics; for example, the topic on $\mathrm{x}$-ray confirmation of device placement depends on the presence of radiology reports. 
Much of our manual work to evaluate topics could be reduced with a combination of NLP and dictionaries of clinical terms. Dictionaries should include standard acronyms and common abbreviations, and should try to account for context when the meaning of a term could be ambiguous. The ability to decipher ongoing care notes will be important for noticing unrecognized signals of AEs.

\section{Conclusions}

Topic analysis of statistically significant words in target documents found records indicative of PAEs, even if the clinician did not explicitly state an outcome was a suspected AE.

Among the PTAEs were unattributed evidence of TACO and TRALI. Some of the mid-2007 to mid-2008 PAEs were increased unattributed events consistent with heparin contamination-related AEs. Our results suggest that heparin contamination may have started before it was officially recognized in the winter of 2007-2008.

This method succeeded despite a wide variety of vocabulary (discipline-specific, context dependence, misspellings, multiple-word expressions, acronyms, personal abbreviations, etc) and formats (sentences, phrases, free lists, formatted lists, etc) used in the text. The Shakespeare method would likely generalize to other EHR notes and other types of medical texts. The computing tools are accessible and openly available. Their application to EHRs broadens the number of types of entities that could independently conduct surveillance of AEs.

It will be useful to adapt NLP methods to automate the abstraction of the notes; the tools will need to be tailored to the various formats used in the notes by different disciplines and individual clinicians. The expansion of vocabulary and acronym lists will also be useful. Automation tools will help to understand how PAEs are distributed within and among topics.

\section{Acknowledgments}

We are thankful for the enthusiastic support by our FDA and Booz Allen Hamilton supervisors, Department of Health and Human Services innovation programs (Ignite Accelerator and Data Science CoLab), and Alistair Johnson, DPhil, of the PhysioNet MIMIC-III program, Massachusetts Institute of Technology Laboratory for Computational Physiology. George Plopper, PhD, of Booz Allen Hamilton, provided project and consultation support. Many FDA colleagues offered ideas and feedback regarding the selection of the case of blood transfusion and the content of this paper.

\section{Authors' Contributions}

All authors had access to the data. All authors were responsible for the study design, interpretation of results, and writing of the paper. RAB, SJB, and LAMP conceived the study and selected the use cases. RAB, SKR, KD, and SVB were responsible for methods development, data processing, and analysis.

\section{Conflicts of Interest}

The research was done with FDA support and under contract HHSF223201510027B between the FDA and Booz Allen Hamilton Inc. None of the authors have other relevant financial interests. The opinions presented in this paper are those of the authors and do not represent official policy of either the FDA or Booz Allen Hamilton.

\section{Multimedia Appendix 1}

Supplementary tables.

[DOCX File, 83 KB-Multimedia Appendix 1]

\section{References}

1. Brewer T, Colditz GA. Postmarketing surveillance and adverse drug reactions: current perspectives and future needs. JAMA 1999 Mar 03;281(9):824-829. [doi: 10.1001/jama.281.9.824] [Medline: 10071004]

2. Scott HD, Thacher-Renshaw A, Rosenbaum SE, Waters WJ, Green M, Andrews LG, et al. Physician reporting of adverse drug reactions. Results of the Rhode Island Adverse Drug Reaction Reporting Project. JAMA 1990 Apr 04;263(13):1785-1788. [Medline: 2313850]

3. Bright RA, Nelson RC. Automated support for pharmacovigilance: a proposed system. Pharmacoepidemiol Drug Saf 2002 Mar;11(2):121-125. [doi: 10.1002/pds.684] [Medline: 11998536]

4. Samore MH, Evans RS, Lassen A, Gould P, Lloyd J, Gardner RM, et al. Surveillance of medical device-related hazards and adverse events in hospitalized patients. JAMA 2004 Jan 21;291(3):325-334. [doi: 10.1001/jama.291.3.325] [Medline: 14734595]

5. Bright RA. Strategy for surveillance of adverse drug events. Food Drug Law J 2007;62(3):605-616. [Medline: 17915403]

6. Hoang T, Liu J, Pratt N, Zheng VW, Chang KC, Roughead E, et al. Authenticity and credibility aware detection of adverse drug events from social media. Int J Med Inform 2018 Dec;120:101-115. [doi: 10.1016/j.ijmedinf.2018.09.002] [Medline: $\underline{30409335]}$ 
7. Classen D, Li M, Miller S, Ladner D. An Electronic Health Record-Based Real-Time Analytics Program For Patient Safety Surveillance And Improvement. Health Aff (Millwood) 2018 Nov;37(11):1805-1812. [doi: 10.1377/hlthaff.2018.0728] [Medline: $\underline{30395491]}$

8. Wang L, Rastegar-Mojarad M, Ji Z, Liu S, Liu K, Moon S, et al. Detecting Pharmacovigilance Signals Combining Electronic Medical Records With Spontaneous Reports: A Case Study of Conventional Disease-Modifying Antirheumatic Drugs for Rheumatoid Arthritis. Front Pharmacol 2018;9:875. [doi: 10.3389/fphar.2018.00875] [Medline: $\underline{\text { 30131701] }}$

9. Alghamdi AA, Keers RN, Sutherland A, Ashcroft DM. Prevalence and Nature of Medication Errors and Preventable Adverse Drug Events in Paediatric and Neonatal Intensive Care Settings: A Systematic Review. Drug Saf 2019 Dec;42(12):1423-1436 [FREE Full text] [doi: 10.1007/s40264-019-00856-9] [Medline: $\underline{\text { 31410745] }}$

10. Molina FJ, Rivera PT, Cardona A, Restrepo DC, Monroy O, Rodas D, et al. Adverse events in critical care: Search and active detection through the Trigger Tool. World J Crit Care Med 2018 Feb 04;7(1):9-15 [FREE Full text] [doi: 10.5492/wjccm.v7.i1.9] [Medline: 29430403]

11. Report to Congress: Update on the adoption of health information technology and related efforts to facilitate the electronic use and exchange of health information. Office of the National Coordinator for Health Information Technology, US Department of Health and Human Services. 2016 Feb. URL: https://www.healthit.gov/sites/default/files/ Attachment_1_-_2-26-16_RTC_Health_IT_Progress.pdf [accessed 2021-06-28]

12. Taggart M, Chapman WW, Steinberg BA, Ruckel S, Pregenzer-Wenzler A, Du Y, et al. Comparison of 2 Natural Language Processing Methods for Identification of Bleeding Among Critically Ill Patients. JAMA Netw Open 2018 Oct 05;1(6): e183451 [FREE Full text] [doi: 10.1001/jamanetworkopen.2018.3451] [Medline: 30646240]

13. Jin Y, Li F, Vimalananda VG, Yu H. Automatic Detection of Hypoglycemic Events From the Electronic Health Record Notes of Diabetes Patients: Empirical Study. JMIR Med Inform 2019 Nov 08;7(4):e14340 [FREE Full text] [doi: 10.2196/14340] [Medline: 31702562 ]

14. Melton GB, Hripcsak G. Automated detection of adverse events using natural language processing of discharge summaries. J Am Med Inform Assoc 2005;12(4):448-457 [FREE Full text] [doi: 10.1197/jamia.M1794] [Medline: 15802475]

15. Patadia VK, Schuemie MJ, Coloma PM, Herings R, van der Lei J, Sturkenboom M, et al. Can Electronic Health Records Databases Complement Spontaneous Reporting System Databases? A Historical-Reconstruction of the Association of Rofecoxib and Acute Myocardial Infarction. Front Pharmacol 2018;9:594 [FREE Full text] [doi: 10.3389/fphar.2018.00594] [Medline: 29928230]

16. Shakespeare W. The Tragedy of Macbeth. New York, NY: Simon \& Schuster; 2013.

17. Craig H, Kinney AF. Shakespeare, Computers, and the Mystery of Authorship. Cambridge, UK: Cambridge University Press; 2009.

18. Young IJB, Luz S, Lone N. A systematic review of natural language processing for classification tasks in the field of incident reporting and adverse event analysis. Int J Med Inform 2019 Dec;132:103971. [doi: 10.1016/j.ijmedinf.2019.103971] [Medline: 31630063]

19. Fortenberry M, Odinet J, Shah P, McKinzie C, Murphy K, Faircloth CB, et al. Development of an electronic trigger tool at a children's hospital within an academic medical center. Am J Health Syst Pharm 2019 Nov 13;76(Supplement_4):S107-S113. [doi: 10.1093/ajhp/zxz222] [Medline: 31724037]

20. Zhou L, Siddiqui T, Seliger SL, Blumenthal JB, Kang Y, Doerfler R, et al. Text preprocessing for improving hypoglycemia detection from clinical notes - A case study of patients with diabetes. Int J Med Inform 2019 Sep;129:374-380. [doi: 10.1016/j.ijmedinf.2019.06.020] [Medline: 31445280]

21. Mesfin YM, Cheng A, Lawrie J, Buttery J. Use of routinely collected electronic healthcare data for postlicensure vaccine safety signal detection: a systematic review. BMJ Glob Health 2019;4(4):e001065 [FREE Full text] [doi: 10.1136/bmjgh-2018-001065] [Medline: 31354969]

22. Morel M, Bacry E, Gaïffas S, Guilloux A, Leroy F. ConvSCCS: convolutional self-controlled case series model for lagged adverse event detection. Biostatistics 2020 Oct 01;21(4):758-774. [doi: 10.1093/biostatistics/kxz003] [Medline: 30851046]

23. Dandala B, Joopudi V, Devarakonda M. Adverse Drug Events Detection in Clinical Notes by Jointly Modeling Entities and Relations Using Neural Networks. Drug Saf 2019 Jan;42(1):135-146. [doi: 10.1007/s40264-018-0764-x] [Medline: $\underline{30649738}]$

24. Wunnava S, Qin X, Kakar T, Sen C, Rundensteiner EA, Kong X. Adverse Drug Event Detection from Electronic Health Records Using Hierarchical Recurrent Neural Networks with Dual-Level Embedding. Drug Saf 2019 Jan;42(1):113-122. [doi: 10.1007/s40264-018-0765-9] [Medline: 30649736]

25. Bagattini F, Karlsson I, Rebane J, Papapetrou P. A classification framework for exploiting sparse multi-variate temporal features with application to adverse drug event detection in medical records. BMC Med Inform Decis Mak 2019 Jan 10;19(1):7 [FREE Full text] [doi: 10.1186/s12911-018-0717-4] [Medline: 30630486]

26. Rafter N, Finn R, Burns K, Condell S, Conroy RM, Hickey A, et al. Identifying hospital-acquired infections using retrospective record review from the Irish National Adverse Events Study (INAES) and European point prevalence survey case definitions. J Hosp Infect 2019 Mar;101(3):313-319. [doi: 10.1016/j.jhin.2018.12.011] [Medline: 30590090] 
27. Li F, Liu W, Yu H. Extraction of Information Related to Adverse Drug Events from Electronic Health Record Notes: Design of an End-to-End Model Based on Deep Learning. JMIR Med Inform 2018 Nov 26;6(4):e12159 [FREE Full text] [doi: 10.2196/12159] [Medline: $\underline{30478023}$ ]

28. Jeong E, Park N, Choi Y, Park RW, Yoon D. Machine learning model combining features from algorithms with different analytical methodologies to detect laboratory-event-related adverse drug reaction signals. PLoS One 2018;13(11):e0207749 [FREE Full text] [doi: 10.1371/journal.pone.0207749] [Medline: 30462745]

29. Santiso S, Perez A, Casillas A. Exploring Joint AB-LSTM With Embedded Lemmas for Adverse Drug Reaction Discovery. IEEE J Biomed Health Inform 2019 Sep;23(5):2148-2155. [doi: 10.1109/JBHI.2018.2879744] [Medline: $\underline{\text { 30403644] }}$

30. Chu J, Dong W, He K, Duan H, Huang Z. Using neural attention networks to detect adverse medical events from electronic health records. J Biomed Inform 2018 Nov;87:118-130 [FREE Full text] [doi: 10.1016/j.jbi.2018.10.002] [Medline: $\underline{30336262]}$

31. Wang SV, Maro JC, Baro E, Izem R, Dashevsky I, Rogers JR, et al. Data Mining for Adverse Drug Events With a Propensity Score-matched Tree-based Scan Statistic. Epidemiology 2018 Nov;29(6):895-903 [FREE Full text] [doi: 10.1097/EDE.0000000000000907] [Medline: 30074538]

32. Martins RR, Silva LT, Bessa GG, Lopes FM. Trigger tools are as effective as non-targeted chart review for adverse drug event detection in intensive care units. Saudi Pharm J 2018 Dec;26(8):1155-1161 [FREE Full text] [doi:

10.1016/j.jsps.2018.07.003] [Medline: 30532636]

33. Whalen E, Hauben M, Bate A. Time Series Disturbance Detection for Hypothesis-Free Signal Detection in Longitudinal Observational Databases. Drug Saf 2018 Jun;41(6):565-577. [doi: 10.1007/s40264-018-0640-8] [Medline: 29468602]

34. Zhou X, Douglas IJ, Shen R, Bate A. Signal Detection for Recently Approved Products: Adapting and Evaluating Self-Controlled Case Series Method Using a US Claims and UK Electronic Medical Records Database. Drug Saf 2018 May;41(5):523-536. [doi: 10.1007/s40264-017-0626-y] [Medline: 29327136]

35. Nydert P, Unbeck M, Pukk Härenstam K, Norman M, Lindemalm S. Drug Use and Type of Adverse Drug Events-Identified by a Trigger Tool in Different Units in a Swedish Pediatric Hospital. Drug Healthc Patient Saf 2020;12:31-40 [FREE Full text] [doi: 10.2147/DHPS.S232604] [Medline: 32099481]

36. Chen L, Gu Y, Ji X, Sun Z, Li H, Gao Y, et al. Extracting medications and associated adverse drug events using a natural language processing system combining knowledge base and deep learning. J Am Med Inform Assoc 2020 Jan 01;27(1):56-64 [FREE Full text] [doi: 10.1093/jamia/ocz141] [Medline: 31591641]

37. Ju M, Nguyen NTH, Miwa M, Ananiadou S. An ensemble of neural models for nested adverse drug events and medication extraction with subwords. J Am Med Inform Assoc 2020 Jan 01;27(1):22-30 [FREE Full text] [doi: 10.1093/jamia/ocz075] [Medline: 31197355]

38. Griffey RT, Schneider RM, Todorov AA. Adverse Events Present on Arrival to the Emergency Department: The ED as a Dual Safety Net. Jt Comm J Qual Patient Saf 2020 Apr;46(4):192-198. [doi: 10.1016/j.jcjq.2019.12.003] [Medline: 32007399]

39. Pandya AD, Patel K, Rana D, Gupta SD, Malhotra SD, Patel P. Global Trigger Tool: Proficient Adverse Drug Reaction Autodetection Method in Critical Care Patient Units. Indian J Crit Care Med 2020 Mar;24(3):172-178 [FREE Full text] [doi: 10.5005/jp-journals-10071-23367] [Medline: 32435095]

40. McIsaac DI, Hamilton GM, Abdulla K, Lavallée LT, Moloo H, Pysyk C, et al. Validation of new ICD-10-based patient safety indicators for identification of in-hospital complications in surgical patients: a study of diagnostic accuracy. BMJ Qual Saf 2020 Mar;29(3):209-216. [doi: 10.1136/bmjqs-2018-008852] [Medline: 31439760]

41. de Vos MS, Hamming JF, Chua-Hendriks JJC, Marang-van de Mheen PJ. Connecting perspectives on quality and safety: patient-level linkage of incident, adverse event and complaint data. BMJ Qual Saf 2019 Mar;28(3):180-189. [doi: 10.1136/bmjqs-2017-007457] [Medline: 30032125]

42. Johnson AEW, Pollard TJ, Shen L, Lehman LH, Feng M, Ghassemi M, et al. MIMIC-III, a freely accessible critical care database. Sci Data 2016;3:160035 [FREE Full text] [doi: 10.1038/sdata.2016.35] [Medline: 27219127]

43. MIMIC-III Critical Care Database. URL: https://mimic.physionet.org/about/mimic/ [accessed 2021-06-28]

44. Bates DW, Cullen DJ, Laird N, Petersen LA, Small SD, Servi D, et al. Incidence of adverse drug events and potential adverse drug events. Implications for prevention. ADE Prevention Study Group. JAMA 1995 Jul 05;274(1):29-34. [Medline: 7791255]

45. Kane-Gill SL, Kirisci L, Verrico MM, Rothschild JM. Analysis of risk factors for adverse drug events in critically ill patients*. Crit Care Med 2012 Mar;40(3):823-828 [FRE Full text] [doi: 10.1097/CCM.0b013e318236f473] [Medline: 22036859]

46. Code of Federal Regulations Title 45 Part 46 Protection of Human Subjects, Subpart A-Basic HHS Policy for Protection of Human Research Subjects, $\$ 46.101$ (b) (4). Department of Health and Human Services. 2000 Oct 1. URL: https://www. govinfo.gov/content/pkg/CFR-2000-title45-vol1/pdf/CFR-2000-title45-vol1-part46.pdf [accessed 2021-06-28]

47. Rankin SK, Bright RA, Dowdy K. Bloatectomy (version v0.0.12). Zenodo. 2020 Jun 26. URL: https://doi.org/10.5281/ zenodo.3909030 [accessed 2021-06-30]

48. Rankin SK, Dowdy K, Bright RA. MIT-LCP/Shakespeare-Method: Macbeth (Version v0.3). Zenodo. 2021 May 26. URL: https://doi.org/10.5281/zenodo.4811611 [accessed 2021-06-30] 
49. Mikolov T, Sutskever I, Chen K, Corrado G, Dean J. Distributed representations of words and phrases and their compositionality. arXiv. Preprint posted online Oct 6, 2013 [FREE Full text]

50. ك̌ehůřek R, Sojka P. Software framework for topic modelling with large corpora. 2010 Presented at: LREC 2010 Workshop on New Challenges for NLP Frameworks; May 22; Valletta, Malta p. 45-50 URL: http://is.muni.cz/publication/884893/en

51. Dejam A, Malley BE, Feng M, Cismondi F, Park S, Samani S, et al. The effect of age and clinical circumstances on the outcome of red blood cell transfusion in critically ill patients. Crit Care 2014 Aug 30;18(4):487 [FREE Full text] [doi: 10.1186/s13054-014-0487-z] [Medline: 25175389]

52. Perrotta PL, Snyder EL. Non-infectious complications of transfusion therapy. Blood Rev 2001 Jun;15(2):69-83. [doi: 10.1054/blre.2001.0151] [Medline: 11409907]

53. Carson JL, Grossman BJ, Kleinman S, Tinmouth AT, Marques MB, Fung MK, Clinical Transfusion Medicine Committee of the AABB. Red blood cell transfusion: a clinical practice guideline from the AABB*. Ann Intern Med 2012 Jul 03;157(1):49-58. [doi: 10.7326/0003-4819-157-1-201206190-00429] [Medline: 22751760]

54. Holness L, Knippen MA, Simmons L, Lachenbruch PA. Fatalities caused by TRALI. Transfus Med Rev 2004 Jul;18(3):184-188. [doi: 10.1016/j.tmrv.2004.03.004] [Medline: 15248168]

55. Menis M, Anderson SA, Forshee RA, McKean S, Johnson C, Holness L, et al. Transfusion-associated circulatory overload (TACO) and potential risk factors among the inpatient US elderly as recorded in Medicare administrative databases during 2011. Vox Sang 2014 Feb;106(2):144-152. [doi: 10.1111/vox.12070] [Medline: 23848234]

56. Menis M, Anderson SA, Forshee RA, McKean S, Johnson C, Warnock R, et al. Transfusion-related acute lung injury and potential risk factors among the inpatient US elderly as recorded in Medicare claims data, during 2007 through 2011. Transfusion 2014 Sep;54(9):2182-2193. [doi: 10.1111/trf.12626] [Medline: 24673344]

57. Bright R, Bright-Ponte S, Palmer L, Blok S. Using diagnosis codes to identify blood transfusion adverse events in electronic health records. medRxiv. Preprint posted online Dec 30, 2020 [FREE Full text] [doi: 10.1101/2020.12.30.20218610]

58. Guyon I, Elisseeff A. An introduction to variable and feature selection. J Mach Learn Res 2003;3:1157-1182 [FREE Full text]

59. Witten IH, Frank E, Hall MA, Pal CJ. Data Mining: Practical Machine Learning Tools and Techniques. San Francisco, CA: Morgan Kaufmann Publishers Inc; 2016.

60. Tang B, Kay S, He H. Toward Optimal Feature Selection in Naive Bayes for Text Categorization. IEEE Trans Knowl Data Eng 2016 Sep 1;28(9):2508-2521 [FREE Full text] [doi: 10.1109/TKDE.2016.2563436]

61. Marafino BJ, Boscardin WJ, Dudley RA. Efficient and sparse feature selection for biomedical text classification via the elastic net: Application to ICU risk stratification from nursing notes. J Biomed Inform 2015 Apr;54:114-120 [FREE Full text] [doi: 10.1016/j.jbi.2015.02.003] [Medline: 25700665]

62. Liu Y, Ju S, Wang J, Su C. A New Feature Selection Method for Text Classification Based on Independent Feature Space Search. Mathematical Problems in Engineering 2020 May 12;2020:1-14. [doi: 10.1155/2020/6076272]

63. Griffiths TL, Steyvers M. Finding scientific topics. Proc Natl Acad Sci U S A 2004 Apr 06;101 Suppl 1:5228-5235 [FREE Full text] [doi: 10.1073/pnas.0307752101] [Medline: 14872004]

64. Carnot ML, Bernardino J, Laranjeiro N, Gonçalo Oliveira H. Applying Text Analytics for Studying Research Trends in Dependability. Entropy (Basel) 2020 Nov 16;22(11):1303 [FREE Full text] [doi: 10.3390/e22111303] [Medline: 33287068]

65. Blei D, Ng A, Jordan M. Latent Dirichlet Allocation. J Mach Learn Res 2003;3:993-1022 [FREE Full text]

66. International Society of Blood Transfusion Working Party on Haemovigilance. Proposed standard definitions for surveillance of non infectious adverse transfusion reactions: Incorporating correction to TRALI definition (as adopted June 2013). International Haemovigilance Network. 2011 Jul. URL: https://tinyurl.com/43bd56ma [accessed 2021-06-28]

67. Sahu S, Hemlata, Verma A. Adverse events related to blood transfusion. Indian J Anaesth 2014 Sep;58(5):543-551 [FREE Full text] [doi: 10.4103/0019-5049.144650] [Medline: 25535415]

68. Juffermans NP, Walsh TS. Introduction. In: Juffermans NP, Walsh TS, editors. Transfusion in the Intensive Care Unit. New York, NY: Springer; 2015:1-4.

69. Preacher KJ, Briggs NE. Calculation for Fisher's exact test: An interactive calculation tool for Fisher's exact probability test for 2 x 2 tables. Quantpsy. 2001 May. URL: http://quantpsy.org/fisher/fisher.htm [accessed 2021-06-28]

70. Varon J. Pulmonary Disorders. In: Handbook of Critical and Intensive Care Medicine, 3rd ed. Cham: Springer; 2016.

71. Krishnamoorthy P, Mukherjee D, Chatterjee S. Red blood cell transfusion trigger in cardiac disease. In: Juffermans NP, Walsh TS, editors. Transfusion in the Intensive Care Unit. New York, NY: Springer; 2015:25-34.

72. Ortega D, Sakr Y. Causes of anemia in critically ill patients. In: Juffermans NP, Walsh TS, editors. Transfusion in the Intensive Care Unit. New York, NY: Springer; 2015:5-12.

73. Carson JL, Hébert P. Anemia and red blood cell transfusion. In: Simon TL, Snyder EL, Solheim BG, Stowell CP, Strauss RG, Petrides M, editors. Rossi's Principles of Transfusion Medicine, 4th ed. Hoboken, NJ: Wiley-Blackwell; 2009:131-148.

74. Raife TJ, Rose JS, Lentz SR. Bleeding from Acquired Coagulation Defects and Antithrombotic Therapy. In: Simon TL, Snyder EL, Solheim BG, Stowell CP, Strauss RG, Petrides M, editors. Rossi's Principles of Transfusion Medicine, 4th ed. Hoboken, NJ: Wiley-Blackwell; 2009:376-390.

75. Snyder MJ, Bepko J, White M. Acute pericarditis: diagnosis and management. Am Fam Physician 2014 Apr 01;89(7):553-560 [FREE Full text] [Medline: 24695601] 
76. Kennedy MS, Wu HM. Transfusion Therapy and Transfusion in Transplantation. In: Harmening D, editor. Modern Blood Banking and Transfusion Practices, 5th ed. Philadelphia, PA: FA Davis Company; 2005:303-321.

77. Reser D, Caliskan E, Tolboom H, Guidotti A, Maisano F. Median Sternotomy. Multimedia Manual of Cardio-Thoracic Surgery. 2015 Jul 17. URL: https://mmcts.org/tutorial/80 [accessed 2021-07-01]

78. Murphy GJ, Patel NN, Sterne JAC. Red Blood Cell Transfusion Trigger in Cardiac Surgery. In: Juffermans NP, Walsh TS, editors. Transfusion in the Intensive Care Unit. New York, NY: Springer; 2015:35-44.

79. Banki F, Estrera AL, Harrison RG, Miller CC, Leake SS, Mitchell KG, et al. Pneumomediastinum: etiology and a guide to diagnosis and treatment. Am J Surg 2013 Dec;206(6):1001-1006. [doi: 10.1016/j.amjsurg.2013.08.009] [Medline: 24296102]

80. Mervis JS, Phillips TJ. Pressure ulcers: Pathophysiology, epidemiology, risk factors, and presentation. J Am Acad Dermatol 2019 Oct;81(4):881-890. [doi: 10.1016/j.jaad.2018.12.069] [Medline: 30664905]

81. Varon J. Critical Care Oncology. In: Handbook of Critical and Intensive Care Medicine. Cham: Springer; 2016:243-262.

82. Goldberg DS, Fallon MB. The Art and Science of Diagnosing and Treating Lung and Heart Disease Secondary to Liver Disease. Clin Gastroenterol Hepatol 2015 Nov;13(12):2118-2127 [FREE Full text] [doi: 10.1016/j.cgh.2015.04.024] [Medline: 25934564]

83. Morris A. Heart-lung interaction via infection. Ann Am Thorac Soc 2014 Jan;11 Suppl 1:S52-S56 [FREE Full text] [doi: 10.1513/AnnalsATS.201306-157MG] [Medline: 24437407]

84. Wallis JP, Sachs UJH. Transfusion - Related Acute Lung Injury. In: Simon TL, Snyder EL, Solheim BG, Stowell CP, Strauss RG, Petrides M, editors. Rossi's Principles of Transfusion Medicine, 4th ed. Hoboken, NJ: Wiley-Blackwell; 2009:870-884.

85. Park YA, Brecher ME. Bacterial Contamination of Blood Products. In: Simon TL, Snyder EL, Solheim BG, Stowell CP, Strauss RG, Petrides M, editors. Rossi's Principles of Transfusion Medicine, 4th ed. Hoboken, NJ: Wiley-Blackwell; 2009:771-790.

86. Vincent JL, Brimioulle S. Topic 2: Resuscitation and Acute Respiratory Failure. In: Critical Care Medicine: Churchill Ready Reference. New York, NY: Churchill Livingstone Elsevier; 2009:5-34.

87. Krueger W, Ludman AJ. Acute Respiratory Distress Syndrome. In: Core Knowledge in Critical Care Medicine. Berlin, Germany: Springer; 2014:99-158.

88. Zhong J, Yang HC, Fogo AB. A perspective on chronic kidney disease progression. Am J Physiol Renal Physiol 2017 Mar 01;312(3):F375-F384 [FREE Full text] [doi: 10.1152/ajprenal.00266.2016] [Medline: 27974318]

89. Davenport RD. Hemolytic Transfusion Reactions. In: Simon TL, Snyder EL, Solheim BG, Stowell CP, Strauss RG, Petrides M, editors. Rossi's Principles of Transfusion Medicine, 4th ed. Hoboken, NJ: Wiley-Blackwell; 2009:811-825.

90. Butcher BW, Liu KD. Fluid overload in AKI: epiphenomenon or putative effect on mortality? Curr Opin Crit Care 2012 Dec;18(6):593-598 [FREE Full text] [doi: 10.1097/MCC.0b013e32835a1c44] [Medline: 23037878]

91. Baxter issues urgent nationwide voluntary recall of heparin 1,000 units/ml 10 and 30ml multi-dose vials NDC NUMBERS 0641-2440-45, 0641-2440-41, 0641-2450-45 and 0641-2450-41; LOTS, 117085, 047056, 097081, 107024, 107064, 107066, 107074, 107111. Food and Drug Administration. 2008 Jan 25. URL: http://wayback.archive-it.org/7993/20170112162456/ http://www.fda.gov/Safety/Recalls/ArchiveRecalls/2008/ucm112352.htm [accessed 2021-06-28]

92. LINEST function. Microsoft Support. 2020. URL: https://support.microsoft.com/en-us/office/ linest-function-84d7d0d9-6e50-4101-977a-fa7abf772b6d [accessed 2021-06-28]

93. Altman DG, Bland JM. How to obtain the P value from a confidence interval. BMJ 2011;343:d2304. [doi: 10.1136/bmj.d2304] [Medline: 22803193]

94. Heparin sodium- heparin sodium injection, solution: Drug label information. DailyMed, US National Library of Medicine. 2020. URL: https://dailymed.nlm.nih.gov/dailymed/drugInfo.cfm?setid=cb1c1e7a-c9ca-4a07-8833-e45ce436d287 [accessed 2021-06-28]

95. Bassareo PP, Cocco D, Bassareo V, Bandino S, Mercuro G. Pharmacological Treatment of Vagal Hyperactivity, a Rare but Potentially Fatal Cause of Sudden Cardiac Death. Mini Rev Med Chem 2018;18(6):483-489. [doi: 10.2174/1389557517666170707102040] [Medline: 28685699]

96. Information on heparin. Food and Drug Administration. 2017. URL: https://wayback.archive-it.org/7993/20170722214801/ https://www.fda.gov/Drugs/DrugSafety/PostmarketDrugSafetyInformationforPatientsandProviders/UCM112597 [accessed 2021-06-28]

97. Centers for Disease Control and Prevention (CDC). Acute allergic-type reactions among patients undergoing hemodialysis--multiple states, 2007-2008. MMWR Morb Mortal Wkly Rep 2008 Mar 08;57(5):124-125 [FREE Full text] [Medline: 18256585]

98. Lyn TE. China pig disease caused by new strain: experts. Reuters. 2007 Jun 26. URL: https://www.reuters.com/article/ us-china-disease-pig-idUSHKG26819620070626 [accessed 2021-06-28]

99. Barboza D. Virus Spreading Alarm and Pig Disease in China. New York Times. 2007 Aug 16. URL: http://www.nytimes.com/ 2007/08/16/business/worldbusiness/16pigs.html [accessed 2021-06-28] 
100. Tian K, Yu X, Zhao T, Feng Y, Cao Z, Wang C, et al. Emergence of fatal PRRSV variants: unparalleled outbreaks of atypical PRRS in China and molecular dissection of the unique hallmark. PLoS One 2007 Jun 13;2(6):e526 [FRE Full text] [doi: 10.1371/journal.pone.0000526] [Medline: 17565379]

101. Levy P. The Harvard medical system. Not Running a Hospital. 2007 Jan 14. URL: http://runningahospital.blogspot.com/ 2007/01/harvard-medical-system.html [accessed 2021-06-28]

102. Schofield A, Magnusson M, Mimno D. Pulling out the stops: rethinking stopword removal for topic models. In: Proceedings of the 15th Conference of the European Chapter of the Association for Computational Linguistics: Volume 2, Short Papers. 2017 Presented at: 15th Conference of the European Chapter of the Association for Computational Linguistics; Apr 3-7; Valencia, Spain p. 432-436 URL: https://www.aclweb.org/anthology/E17-2069 [doi: 10.18653/v1/e17-2069]

103. Halamka J. What will keep me up at night. Dispatch from the digital health frontier. 2007 Nov. URL: http://geekdoctor. blogspot.com/2007/11/ [accessed 2021-06-28]

104. Speier W, Ong MK, Arnold CW. Using phrases and document metadata to improve topic modeling of clinical reports. J Biomed Inform 2016 Jun;61:260-266 [FREE Full text] [doi: 10.1016/j.jbi.2016.04.005] [Medline: 27109931]

105. Cohen R, Aviram I, Elhadad M, Elhadad N. Redundancy-aware topic modeling for patient record notes. PLoS One 2014;9(2):e87555 [FREE Full text] [doi: 10.1371/journal.pone.0087555] [Medline: 24551060]

106. Pérez J, Pérez A, Casillas A, Gojenola K. Cardiology record multi-label classification using latent Dirichlet allocation. Computer Methods and Programs in Biomedicine 2018 Oct;164:111-119. [doi: 10.1016/j.cmpb.2018.07.002]

107. Ahuja Y, Zhou D, He Z, Sun J, Castro VM, Gainer V, et al. sureLDA: A multidisease automated phenotyping method for the electronic health record. J Am Med Inform Assoc 2020 Aug 01;27(8):1235-1243. [doi: 10.1093/jamia/ocaa079] [Medline: 32548637]

108. Arnold C, Speier W. A Topic Model of Clinical Reports. In: Proceedings of the 35th International ACM SIGIR Conference on Research and Development in Information Retrieval. 2012 Presented at: SIGIR '12; Aug 12; Portland, OR p. $1031-1032$. [doi: 10.1145/2348283.2348454]

109. Poulin C, Shiner B, Thompson P, Vepstas L, Young-Xu Y, Goertzel B, et al. Predicting the risk of suicide by analyzing the text of clinical notes. PLoS One 2014;9(1):e85733 [FREE Full text] [doi: 10.1371/journal.pone.0085733] [Medline: 24489669]

110. Wang Y, Zhao Y, Therneau TM, Atkinson EJ, Tafti AP, Zhang N, et al. Unsupervised machine learning for the discovery of latent disease clusters and patient subgroups using electronic health records. J Biomed Inform 2020 Feb;102:103364 [FREE Full text] [doi: 10.1016/j.jbi.2019.103364] [Medline: 31891765]

111. Rumshisky A, Ghassemi M, Naumann T, Szolovits P, Castro VM, McCoy TH, et al. Predicting early psychiatric readmission with natural language processing of narrative discharge summaries. Transl Psychiatry 2016 Oct 18;6(10):e921 [FREE Full text] [doi: 10.1038/tp.2015.182] [Medline: 27754482]

112. Huang Z, Dong W, Duan H. A probabilistic topic model for clinical risk stratification from electronic health records. J Biomed Inform 2015 Dec;58:28-36 [FREE Full text] [doi: 10.1016/j.jbi.2015.09.005] [Medline: 26370451]

113. Boag W, Kovaleva O, McCoy TH, Rumshisky A, Szolovits P, Perlis RH. Hard for humans, hard for machines: predicting readmission after psychiatric hospitalization using narrative notes. Transl Psychiatry 2021 Jan 11;11(1):32 [FREE Full text] [doi: 10.1038/s41398-020-01104-w] [Medline: 33431794]

114. Ghassemi M, Naumann T, Doshi-Velez F, Brimmer N, Joshi R, Rumshisky A, et al. Unfolding Physiological State: Mortality Modelling in Intensive Care Units. KDD 2014 Aug 24;2014:75-84 [FREE Full text] [doi: 10.1145/2623330.2623742] [Medline: 25289175]

115. Howes C, Purver M, McCabe R. Investigating Topic Modelling for Therapy Dialogue Analysis. In: Proceedings of the IWCS 2013 Workshop on Computational Semantics in Clinical Text. 2013 Presented at: CSCT 2013; Mar 19; Potsdam, Germany p. 7-16 URL: https://www.aclweb.org/anthology/W13-0402

116. Halpern Y, Horng S, Nathanson LA, Shapiro NI, Sontag D. A comparison of dimensionality reduction techniques for unstructured clinical text. 2012 Presented at: ICML Workshop on Clinical Data Analysis; June 30-July 1; Edinburgh, Scotland URL: http://people.csail.mit.edu/dsontag/papers/HalpernEtAl_icml12_workshop.pdf [doi: $\underline{10.1142 / 97898143835090014]}$

117. Steyvers M, Griffiths T. Probabilistic Topic Models. In: Landauer T, McNamara D, Dennis S, Kintsch W, editors. Latent Semantic Analysis: A Road to Meaning. Mahwah, NJ: Laurence Erlbaum; 2007.

118. Arnold CW, El-Saden SM, Bui AAT, Taira R. Clinical Case-based Retrieval Using Latent Topic Analysis. AMIA Annu Symp Proc 2010 Nov 13;2010:26-30 [FREE Full text] [Medline: 21346934]

\section{Abbreviations}

AE: adverse event

C: comparison group

EHR: electronic health care record

FDA: Food and Drug Administration

LDA: latent Dirichlet allocation 
LR: logistic regression

MIMIC-III: Medical Information Mart for Intensive Care III

NB: naïve Bayes

NLP: natural language processing

PAE: potential adverse event

PTAE: potential transfusion adverse event

T: transfusion group

TACO: transfusion-associated circulatory overload

TAE: transfusion adverse event

tPA: tissue plasminogen activator

TRALI: transfusion-related acute lung injury

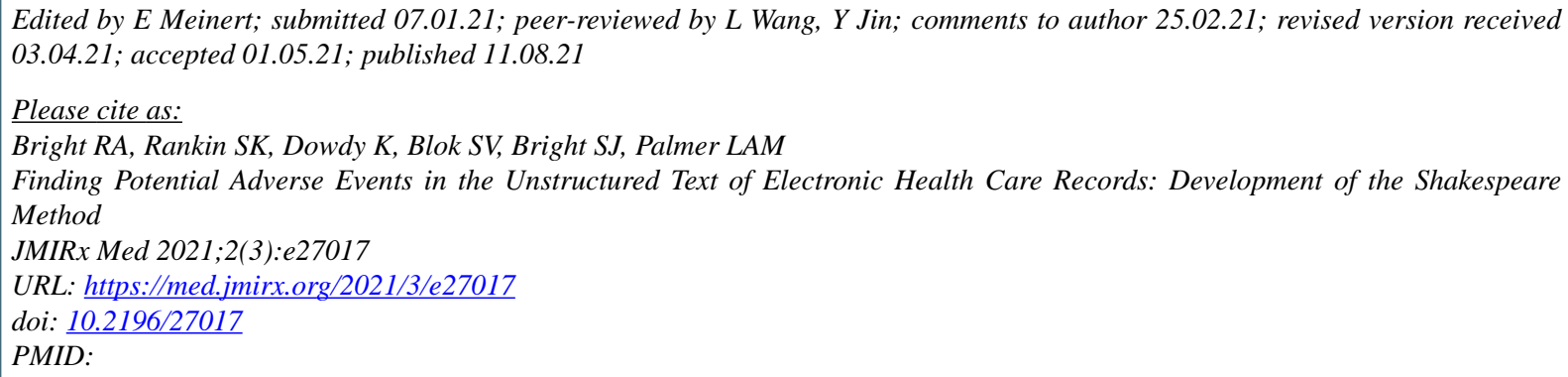

(CRoselie A Bright, Summer K Rankin, Katherine Dowdy, Sergey V Blok, Susan J Bright, Lee Anne M Palmer. Originally published in JMIRx Med (https://med.jmirx.org), 11.08.2021. This is an open-access article distributed under the terms of the Creative Commons Attribution License (https://creativecommons.org/licenses/by/4.0/), which permits unrestricted use, distribution, and reproduction in any medium, provided the original work, first published in JMIRx Med, is properly cited. The complete bibliographic information, a link to the original publication on https://med.jmirx.org/, as well as this copyright and license information must be included. 